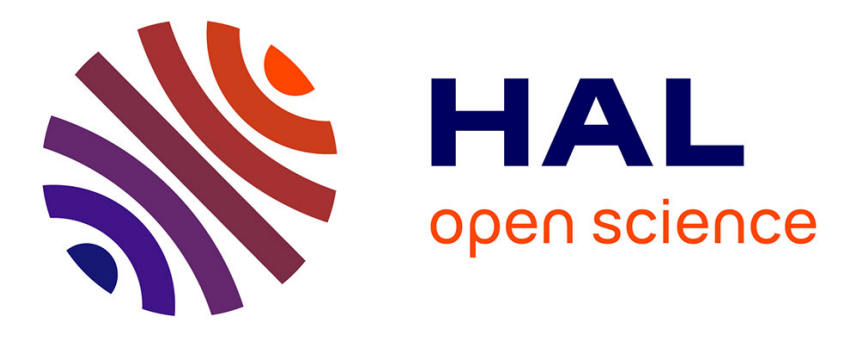

\title{
Influence of anthropogenic emission inventories on simulations of air quality in China during winter and summer 2010
}

Idir Bouarar, Guy Brasseur, Katinka Petersen, Claire Granier, Lili Wang, Ying Xie, Qi Fan, Xuemei Wang, Dongsheng Ji, Zirui Liu, et al.

\section{To cite this version:}

Idir Bouarar, Guy Brasseur, Katinka Petersen, Claire Granier, Lili Wang, et al.. Influence of anthropogenic emission inventories on simulations of air quality in China during winter and summer 2010. Atmospheric Environment, 2019, 198, pp.236-256. 10.1016/j.atmosenv.2018.10.043 . hal-02116043

\section{HAL Id: hal-02116043 \\ https://hal.science/hal-02116043}

Submitted on 10 Nov 2020

HAL is a multi-disciplinary open access archive for the deposit and dissemination of scientific research documents, whether they are published or not. The documents may come from teaching and research institutions in France or abroad, or from public or private research centers.
L'archive ouverte pluridisciplinaire HAL, est destinée au dépôt et à la diffusion de documents scientifiques de niveau recherche, publiés ou non, émanant des établissements d'enseignement et de recherche français ou étrangers, des laboratoires publics ou privés. 
Atmospheric Environment

Elsevier Editorial System(tm) for

Manuscript Draft

Manuscript Number: ATMENV-D-18-00596

Title: Modelling trace gas and aerosol distribution in China during winter and summer 2010

Article Type: Research Paper

Keywords: Air quality modelling; WRF-Chem; PM2.5; Ozone; Anthropogenic Emissions

Corresponding Author: Dr. Idir Bouarar,

Corresponding Author's Institution: Max Planck Institute for Meteorology

First Author: Idir Bouarar

Order of Authors: Idir Bouarar; Guy Brasseur; Katinka Petersen; Claire Granier; Lili Wang; Ying Xie; Fan Qi; Xuemei Wang; Dongsheng Ji; Zirui Liu; Wei Gao

Abstract: We applied the regional chemistry-transport model WRF-Chem to investigate the air pollution characteristics in three Chinese city clusters (Beijing, Shanghai and Guangzhou) and assess the model performance in wintertime (January 2010) and summertime (July 2010) conditions. Three simulations utilizing the HTAPv2, REASv2 and MACCity anthropogenic emission inventories were conducted and compared with satellite and ground-based measurements to assess the sensitivity of the model predictions to anthropogenic emissions. Model-predicted surface meteorological fields are overall in good agreement with surface observations, although the model tends to overestimate the maximum values of surface wind speed as reported also in previous WRF-Chem modelling studies. Large discrepancies between the three emission inventories were found, specifically in the spatial distribution and the magnitude of the emissions (e.g. over 98\%, 86\% and 85\% differences in some regions for carbon monoxide (CO), nitrogen oxide (NO) and organic carbon (OC) emissions respectively). As a result, we found large differences between the simulations and several discrepancies when compared to satellite and surface observations. The HTAPV2- and REASV2-based simulations better reproduce the magnitude and spatial features of CO total columns and NO2 tropospheric columns derived from MOPITTV6 and GOME2 satellite observations respectively. The three model simulations satisfactorily reproduce the air pollution characteristics in January 2010 as observed at surface monitoring stations in Beijing and Shanghai, and meet the air quality model performance goals for particulates. The HTAPv2-based simulation better captures the pollution episode that occurred in Beijing in mid-January 2010, which is found to be related to a combination of different meteorological factors that led to the build-up of pollution. The high photochemical activity and convective turbulence in July 2010, in addition to differences in the emissions used, led to more pronounced differences between the three simulations and lower statistical skills in particular for trace gases.

This study shows that a considerable part of uncertainties in current air quality model predictions for China can be attributed to uncertainties in 
emissions estimates in the anthropogenic emission inventories. It highlights the need for more accurate and highly resolved emissions in order to improve the accuracy of the model predictions. This study reveals however that in some cases, model-observation discrepancies cannot be attributed only to inaccuracies in the emissions. For example, we found that regardless of the adopted emissions, all the simulations failed to capture the variability of particulate matter in Guangzhou in January 2010 indicating that other factors than emissions have a considerable influence on the atmospheric composition in this region. This work shows that inaccuracies in the predicted meteorological parameters (e.g. wind speed/direction, relative humidity, etc.) can significantly affect the model performance as found for example in the model predictions for Shanghai for July 2010, which showed high and abrupt increases of NOx and particulates due to rapid decreases in wind speed in the model. 
April $10^{\text {th }}, 2018$

Dear Editor,

I, as corresponding author on behalf of all the authors, am submitting a manuscript entitled: Modelling trace gas and aerosol distribution in China during winter and summer 2010. Please accept the manuscript for consideration to be published in the journal Atmospheric Environment.

The manuscript, which is in the scope of Atmospheric Environment, is a research paper to investigate the air pollution characteristics in three polluted cities in China (Beijing, Shanghai and Guangzhou) in winter and summer conditions using the regional WRF-Chem model simulations combined with ground-based and satellite measurements. The ability of WRF-Chem to reproduce the distributions and concentrations of pollutants in Eastern China and to capture specific pollution events under specific meteorological conditions is assessed. The study shows the uncertainties in current air quality model predictions for China related to uncertainties in estimates of anthropogenic emissions in the current inventories. It highlights the need for more accurate and highly resolved emissions in order to improve the accuracy of the model predictions. The study demonstrates also the considerable impact of inaccuracies in the prediction of meteorological situations on the performance and statistical skills of the air quality predictions. The study provided also an opportunity to assess the performance of the selected WRF-Chem model settings, which led to the implementation of the model as an operational forecasting system for regional air quality in China.

We affirm that this manuscript is original, has not been published before and is not currently being considered for publication elsewhere.

Sincerely yours,

Idir Bouarar

Max Planck Institute for Meteorology

Environmental Modeling

Bundesstr. 53

D-20146 Hamburg

Germany

E-mail: idir.bouarar@mpimet.mpg.de

Tel.: +49-(0)40-41173-411 


\section{Modelling trace gas and aerosol distribution in China during winter and summer 2010}

3 Idir Bouarar $^{1}$, Guy Brasseur ${ }^{1}$, Katinka Petersen ${ }^{1}$, Claire Granier ${ }^{2,3}$, Qi Fan ${ }^{4}$, Xuemei Wang ${ }^{5}$, Lili Wang ${ }^{6}$,

$4{\text { Dongsheng } \mathrm{Ji}^{6} \text {, Zirui Liu }}^{6}$, Ying Xie ${ }^{7}$, Wei Gao ${ }^{7}$

$5 \quad{ }^{1}$ Max Planck Institute for Meteorology, Hamburg, Germany

$6 \quad$ 2Laboratoire d'Aérologie, CNRS-UPS, Toulouse, France

$7{ }^{3}$ NOAA ESRL/CSD and CIRES, University Colorado, Boulder, USA

$8{ }^{4}$ Sun Yat-Sen University, School Of Environmental Science and Engineering (SESE-SYSU), Guangzhou, China

$9 \quad{ }^{5}$ Institute for Environmental and Climate Research, Jinan University, Guangzhou, China

$10{ }^{6}$ State Key Laboratory of Atmospheric Boundary Layer Physics and Atmospheric Chemistry, Institute of Atmospheric Physi 11 cs, Chinese Academy of Sciences, Beijing, China

$12{ }^{7}$ Yangtze River Delta Center for Environmental Meteorology Prediction and Warning, Shanghai Meteorological

13 Service, Shanghai, China

Correspondence to: Idir Bouarar (idir.bouarar@mpimet.mpg.de)

\section{Abstract}

17 We applied the regional chemistry-transport model WRF-Chem to investigate the air pollution 18 characteristics in three Chinese city clusters (Beijing, Shanghai and Guangzhou) and assess the model performance in wintertime (January 2010) and summertime (July 2010) conditions. Three simulations compared with satellite and ground-based measurements to assess the sensitivity of the model predictions to anthropogenic emissions. Model-predicted surface meteorological fields are overall in good agreement with surface observations, although the model tends to overestimate the maximum values of surface wind speed as reported also in previous WRF-Chem modelling studies. Large discrepancies between the three emission inventories were found, specifically in the spatial distribution and the magnitude of the emissions (e.g. over 98\%, 86\% and $85 \%$ differences in some regions for carbon monoxide (CO), nitrogen oxide (NO) and organic carbon (OC) emissions respectively). As a result, we found large differences between the simulations and several discrepancies when compared to satellite and surface observations. The HTAPv2- and REASv2-based simulations better reproduce the magnitude and spatial features of $\mathrm{CO}$ total columns and $\mathrm{NO}_{2}$ tropospheric columns derived from 
MOPITTv6 and GOME2 satellite observations respectively. The three model simulations satisfactorily reproduce the air pollution characteristics in January 2010 as observed at surface monitoring stations in Beijing and Shanghai, and meet the air quality model performance goals for particulates. The HTAPv2based simulation better captures the pollution episode that occurred in Beijing in mid-January 2010, which is found to be related to a combination of different meteorological factors that led to the build-up of pollution. The high photochemical activity and convective turbulence in July 2010, in addition to differences in the emissions used, led to more pronounced differences between the three simulations and lower statistical skills in particular for trace gases.

This study shows that a considerable part of uncertainties in current air quality model predictions for China can be attributed to uncertainties in emissions estimates in the anthropogenic emission inventories. It highlights the need for more accurate and highly resolved emissions in order to improve the accuracy of the model predictions. This study reveals however that in some cases, modelobservation discrepancies cannot be attributed only to inaccuracies in the emissions. For example, we found that regardless of the adopted emissions, all the simulations failed to capture the temporal variability of particulate matter in Guangzhou in January 2010 indicating that other factors than emissions have a considerable influence on the atmospheric composition in this region. This work shows that inaccuracies in the predicted meteorological parameters (e.g. wind speed/direction, relative humidity, etc.) can significantly affect the model performance as found for example in the model predictions for Shanghai for July 2010, which showed high and abrupt increases of NOx and particulates due to rapid decreases in wind speed in the model.

Keywords: Air quality modelling; WRF-Chem; $\mathrm{PM}_{2.5}$; Ozone; Anthropogenic Emissions

\section{Introduction}

Air pollutants such as ozone $\left(\mathrm{O}_{3}\right)$, nitrogen oxides $(\mathrm{NOx})$, carbon monoxide $(\mathrm{CO})$, sulfur dioxide $\left(\mathrm{SO}_{2}\right)$ and particulate matter $\left(\mathrm{PM}_{2.5}\right.$ and $\left.\mathrm{PM}_{10}\right)$ are known to have severe and acute effects on human health. Several studies have shown a wide range of these effects extending from minor respiratory infections and bronchitis to chronic effects, heart and vascular diseases and even lung cancer (Kampa and Castanas 2008; Hamra et al. 2015). Air pollutants are known to have also adverse consequences on agriculture by reducing productivity and crop yields in response to acid precipitation and dry deposition 
61 of ozone and other pollutants (Ashmore, 2005; Leisner et al., 2012; Sinha et al., 2015). Other adverse

effects include reduction in visibility, forest damage, eutrophication of water resources, and damages to buildings and historical monuments. Air pollutants contribute also to global warming due to direct and indirect radiative forcing (Sitch et al. 2007), thus affecting climate change (Brasseur et al., 1999; Akimoto, 2003).

China has been experiencing rapid industrialization for more than three decades. During the course of this expansion, urbanization and consequently energy needs increased, causing significant impacts on the environment including air and water quality degradation. Among the environmental issues in China, air quality has become a major problem and several studies and efforts have been devoted to elucidate the reasons behind the extremely high pollution events that occur frequently in China. Bouarar et al. (2017) presented an integrated view of past and present situations in China and a comprehensive analysis of the chemical and meteorological processes responsible for the formation of air pollutants in eastern Asia. Guo et al. (2014) showed that, although observed chemical compositions of particles in Beijing are similar to those observed in other regions of the world, this city and likely other urban areas in China are characterised by particular aerosol formation mechanisms leading to high $\mathrm{PM}_{2.5}$. Based on in-situ observations, Huang et al. (2014) analysed the chemical nature and source of $\mathrm{PM}_{2.5}$ in urban locations in China during the extremely severe haze pollution in January 2013, and found that secondary aerosol formation was the main contribution to this haze pollution event. Wang et al. (2014) concluded that secondary aerosol formation is an important mechanism in the development of heavy haze episodes. Specific meteorological conditions together with specific geographical characteristics can lead to air stagnation and low mixing in the boundary layer, which reduce the dispersion of pollution and thus lead to pollution accumulation near the surface (Wang et al., 2014; Zhao et al., 2013; Bouarar et al., 2017).

Air quality issues in China have also become a major concern for many other countries that are directly affected through long-range transport of pollution. The close countries such as Japan and Korea are the first affected by pollution transported downwind from eastern China (Kurokawa et al., 2009; Osada et al., 2009; Chatani and Sudo, 2011; Geng et al., 2014). Several studies on transport pathways of pollution have demonstrated the transpacific transport of East Asian emissions and their potential contribution to pollution episodes in western USA (Jacob et al, 1999; Liang et al. 2004; Zhang et al., 2009; Lin et al., 2012). Stohl et al. (2007) showed that air pollution plumes from Southeast Asia can 
also reach the upper troposphere in Europe. Detailed pathways of pollutants export originating in east Asia are identified and analysed in UNECE (2010), showing that air pollution in Asia affects other regions of the world.

Air quality models, with their ability to simulate the physical and chemical processes that affect air pollution, are powerful tools used together with observational datasets to address the complex chemical processes and source and dispersion of pollution within the atmosphere (Brasseur and Jacob, 2017). They are also important tools for air quality management and policy assessments, and can assist for defining effective strategies and plans to mitigate air pollution. Mesoscale models have been increasingly used to investigate air pollution characteristics in many countries especially in Asia. Xu et al. (2008) analysed the chemical regimes responsible for summertime $\mathrm{O}_{3}$ formation in the Beijing area using an air quality model. Liao et al. (2014), showed a clear sensitivity of regional simulation of $\mathrm{O}_{3}$, particles and meteorological variables in the Yangtze River Delta region to urban canopy parameterisations. Fan et al. (2015) analysed three pollution episodes in the Pearl River Delta region based on air quality model simulations, and demonstrated the impact of local emissions and the role of weather conditions, such as high humidity and cloud processes, in the formation of fine secondary particles. Wang et al. (2010) showed that seasonal, day-of-week, diurnal and vertical allocations of anthropogenic emissions can significantly change the simulated distribution of $\mathrm{NOx}, \mathrm{SO}_{2}$ and $\mathrm{O}_{3}$ concentrations in a mesoscale model. From the analysis of their global and regional model results, Quennehen et al. (2016) investigated the distribution of pollutants in summer 2008 and showed that, despite some similarities (e.g. overestimation of surface $\mathrm{NO}_{2}$ ), the accuracy of simulated $\mathrm{O}_{3}$ and aerosol patterns often vary considerably among the models.

Despite several modelling studies that have focused on air pollution events in China, the complex formation mechanisms of acute events still need to be elucidated, and the state-of-the-art chemical transport models are still unable to predict correctly the magnitude and characteristics of such pollution episodes. Model treatments of processes affecting the lifetime, formation and dispersion of pollutants still need to be improved (Quennehen et al., 2016; Bouarar et al., 2017). Other uncertainties in air quality model predictions are related to model input datasets including initial and boundary conditions, meteorological data and surface emission fluxes. For the latter, there are numerous inventories providing estimates of surface emissions at both the global and regional scales. However, several assessments of the quality of such datasets exhibit large differences not only in the estimated total 
amounts (Kurokawa et al., 2013) but also in the spatial and temporal distributions of past, present and future emissions (Granier et al. 2011). Differences in estimates of activity data and emissions factors for different sources and sectors are among the possible reasons of discrepancies between the inventories (Granier et al., 2017).

Previous modelling studies either focused on a specific region of Asia, a specific pollution event and period, or analysed observations and model results only for some specific chemical species. Moreover, only few studies have been dedicated to the impact of uncertainties in emissions inventories on air quality model results particularly in Asia (e.g. Amnuaylojaroen et al., 2014). In the present study, we investigate the distribution of air pollutants in three major urban areas: Beijing, Shanghai and Guangzhou. These regions have experienced intense urbanization and population growth during the last decades and are among the most polluted areas of China (Wu et al., 2012; Boynard et al., 2014). We investigate specifically the sensitivity of WRF-Chem air quality predictions to uncertainties in emissions using three anthropogenic emission inventories. The HTAPv2 inventory (developed within the Task Force Hemispheric Transport of Air Pollution initiative TF HTAP) is being used in many modelling activities including the WRF-Chem operational air quality forecasting system that we implemented within the framework of the EU FP7 project PANDA (www.marcopolo-panda.eu). The MACCity inventory (developed within the MACC and CityZen EU projects) is currently used by the Copernicus Atmospheric Monitoring Service (CAMS) (Flemming et al., 2009, 2017). REASv2 (Regional Emission Inventory in Asia version 2) is among the first inventories that provided emissions at high spatial resolution for several East Asian countries. We analyse the model results and the observations of $\mathrm{PM}_{2.5}, \mathrm{PM}_{10}, \mathrm{O}_{3}, \mathrm{NOx}, \mathrm{CO}$ and $\mathrm{SO}_{2}$ concentrations in the three selected regions in both winter and summer conditions (specifically for January and July 2010). During wintertime, stable and stagnant conditions, occurring in particular in northern China, constitute a favorable environment for the accumulation of pollutants, and lead to persistent haze events. Photochemical activity, which increases during summertime, leads to enhanced ozone concentrations.

The specific objectives of the present study are (1) to assess the ability of the selected WRF-Chem configuration (see Sect. 2.1) to reproduce the distributions and concentrations of pollutants in Eastern China in both summer and winter conditions, (2) to investigate the ability of the model to capture specific pollution events under specific meteorological conditions, (3) to investigate the air quality 
responses to changes in emissions through sensitivity studies to anthropogenic emission inventories, (4) to identify shortcomings that need to be addressed to improve the air quality model predictions.

A detailed description of the selected WRF-Chem configuration and of the evaluation datasets are given in Section 2. Section 3 presents an evaluation of the representation of meteorological situations by the model. A comparison of the HTAPv2, REASv2 and MACCity anthropogenic emission inventories and an evaluation of their influence on simulated spatial distributions of pollutants are presented in Section 4. The model simulations are evaluated against surface measurements of pollutants in Section 5. Section 6 presents a summary and conclusions of the present work and suggestions for future research activities.

\section{Model description and evaluation datasets}

\subsection{Model configuration}

WRF-Chem is the Weather Research and Forecasting (WRF) model (Skamarock et al., 2008) coupled to chemistry (Grell et al., 2005; Fast et al., 2006). For this study, we used version 3.6.1 to simulate the meteorology and chemistry simultaneously in the model domains shown on Figure 1. Domain D01 with $60 \mathrm{~km}$ horizontal grid spacing extends from India to the Pacific Ocean and from Malaysia to southern Russia to cover the most polluted areas in Asia. Domain D02 covers the eastern part of China with a 20 $\mathrm{km}$ grid resolution. The vertical grid is composed of 51 levels extending from the surface to $10 \mathrm{hPa}$ $(\sim 30 \mathrm{~km})$ with a spacing of about 40-50 m near the surface, $200-450 \mathrm{~m}$ for altitudes around 1-3 km and 500-700 $\mathrm{m}$ for altitudes between 4 and $14 \mathrm{~km}$. The resolved scale cloud physics is represented by the Thompson microphysics scheme (Thompson et al., 2004, 2008) and sub-grid scale effects of convective and shallow clouds are parameterized according to Grell and Freitas (2014). The short- and long-wave radiative transfer in the atmosphere are represented by the Goddart scheme (Chou et al., 1998) and the Rapid Radiative Transfer Model (RRTM) (Mlawer et al., 1997) respectively. For surface processes, the model setup uses the NOAH land-surface model (Chen and Dudhia, 2001) and the revised MM5 Monin-Obukhov surface layer scheme. The vertical sub-grid scale fluxes due to eddy transport in the planetary boundary layer (PBL) and the free troposphere are parameterized according to the Yonsei University (YSU) boundary layer scheme (Hong et al., 2006).

The gas-phase chemistry is represented by the Model for Ozone and Related Chemical Tracers (MOZART-4) chemical scheme (Emmons et al., 2010). The Goddard Chemistry Aerosol Radiation and Transport (GOCART) aerosol module coupled with MOZART is used in this study to take into account 
the aerosol processes. GOCART is a bulk aerosol model (Chin et al., 2002; Ginoux et al., 2001) and provides total mass information on sulfate, organic and black carbon, $\mathrm{PM}_{2.5}$ and $\mathrm{PM}_{10}$. It includes also a sectional scheme for dust (5 bins) and sea salt (4 bins). The GOCART model is numerically efficient and useful for process studies focused on both gas phase and aerosol chemistry. The model configuration used in this study, with the exception of the GOCART aerosol scheme, which has been replaced by the MOSAIC scheme (Zaveri et al., 2008), was successfully implemented to provide daily operational air quality forecasts in China, available at http://www.marcopolo-panda.eu.

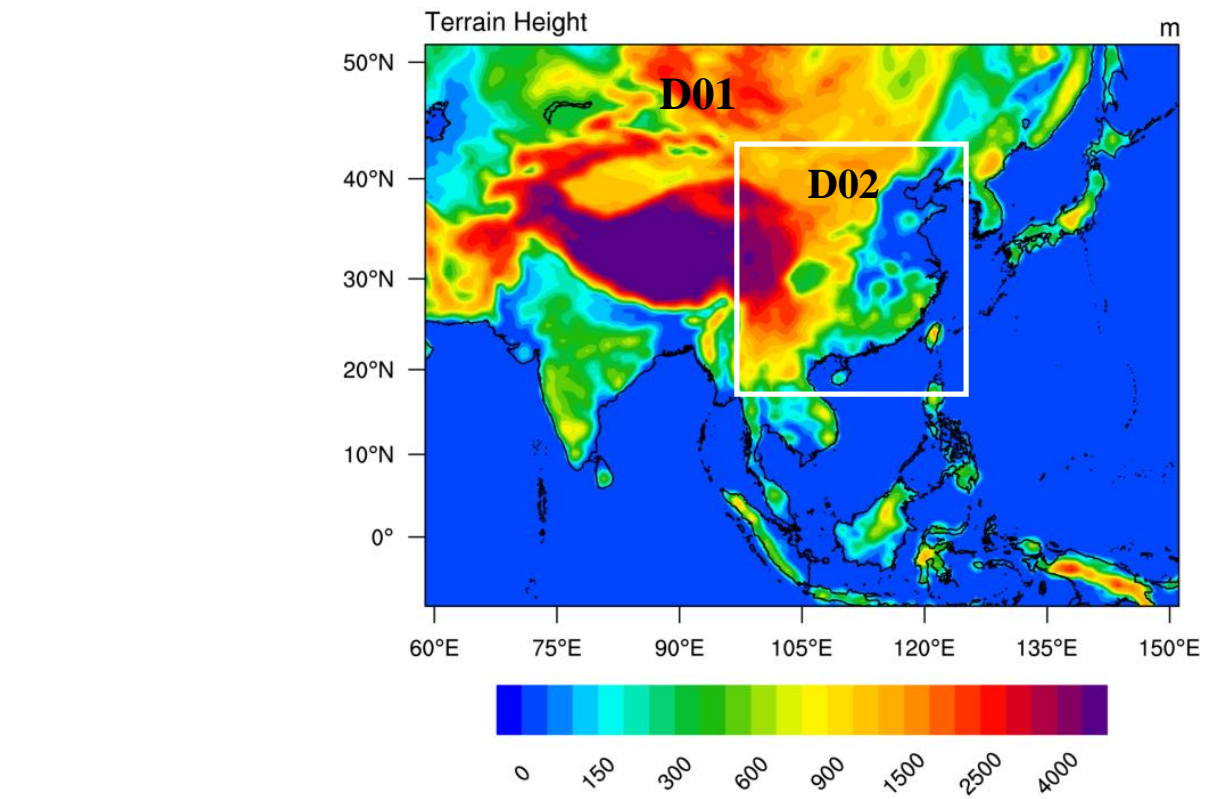

Figure 1: Terrain height (m) over East Asia and WRF-Chem model domain settings.

\subsection{Model input datasets}

The initial and lateral boundary conditions for the meteorological variables are obtained from the National Center for Environmental Predictions and Final Analysis (NCEP-FNL) available every 6 hours at $1^{\circ} \times 1^{\circ}$ spatial resolution. For the chemical and aerosol species, initial and lateral boundary conditions are provided by the global operational forecasting system implemented within the EU MACC (now CAMS, https://atmosphere.copernicus.eu) project (Flemming et al., 2009, 2015). The MACC system is constrained by assimilation of $\mathrm{CO}, \mathrm{O}_{3}$ and $\mathrm{NO}_{2}$ observations from several satellite instruments using the ECMWF 4D-Var assimilation system (Inness et al., 2013). This makes the MACC products, which are 
also based on the MOZART model, ideal for use in regional coupled models. Missing species in the

MACC datasets, such as some VOCs, are provided by the MOZART-4 global model forecasts performed routinely at the National Center for Atmospheric Research (NCAR) (http://www.acom.ucar.edu/wrf-chem/mozart.shtml). This model includes a detailed formulation of VOC speciation and aerosol concentrations (Emmons et al., 2010). Both MACC/CAMS and MOZART4 chemical data forecasts are frequently used to derive several regional air quality forecasting systems across the world with initial and lateral boundary conditions.

As mentioned in the previous sections, three anthropogenic emissions inventories are considered in this study. The HTAPv2 emissions inventory consists of $0.1^{\circ} \times 0.1^{\circ}$ gridmaps of several species including $\mathrm{CO}, \mathrm{SO}_{2}, \mathrm{NO}, \mathrm{NMVOC}, \mathrm{NH}_{3}, \mathrm{BC}$ and $\mathrm{OC}$ for the years 2008 and 2010. The dataset is available on the ECCAD data portal (http://eccad.aeris-data.fr). It has been constructed using nationally reported emissions combined with regional scientific inventories in the format of sector-specific gridmaps. For China, it includes the Multi-resolution Emission Inventory for China (MEIC), which is available at http://www.meicmodel.org. Detailed description and qualitative assessment of the HTAPv2 emissions are provided in Janssens-Maenhout et al. (2015).

The REASv2.1 inventory has been developed since 2007 for the analysis of long-term trends of the Asian atmospheric environment (Kurokawa et al., 2013). This dataset includes most major air pollutants and greenhouse gases for the following areas in Asia: East, Southeast, South, and Central Asia and the Asian part of Russia. Monthly gridded data with a $0.25^{\circ} \times 0.25^{\circ}$ resolution are provided for the major emissions sectors and are available at http://www.nies.go.jp/REAS/.

MACCity is a global emissions inventory developed in the framework of the European MACC and CityZen projects. It provides emissions of several species including $\mathrm{CO}, \mathrm{NOx}, \mathrm{SO}_{2}, \mathrm{NH}_{3}, \mathrm{OC}$ and $\mathrm{BC}$ and NMVOC (Granier et al., 2011). The monthly gridded emission data with a resolution of $0.5^{\circ} \times 0.5^{\circ}$ for the major sectors are available on the ECCAD web portal.

Three WRF-Chem simulations, hereafter named HTP, RAS and MCT, using separately the emissions HTAPv2, REASv2 and MACCity, respectively, are performed and analysed in this study. In addition to anthropogenic emissions, daily varying emissions of trace species from biomass burning were taken from the Fire Inventory from NCAR version 1 (FINN v1) (Wiedinmyer et al., 2011). They are distributed vertically in the model following the online plume-rise module (Freitas et al., 2007). Biogenic emissions of trace species from terrestrial ecosystems are calculated online using the Model of 
Emissions of Gases and Aerosols from Nature (MEGAN) version 2.04 (Guenther et al., 2006). Dust and seas salt are simulated using the GOCART emission scheme (Ginoux et al., 2001).

\subsection{Observational datasets and evaluation methodology}

For the evaluation of the model performance, satellite data as well as surface measurements made available within the PANDA project are used to assess both the spatial distribution and temporal variation of pollutants. Evaluation of the spatial patterns is performed by comparing the simulated total $\mathrm{CO}$ columns and tropospheric $\mathrm{NO}_{2}$ columns against MOPITTv6 (Deeter et al., 2014) and GOME2 (Callies et al., 2000; Boersma et al., 2004) satellite observations respectively. Evaluation of the temporal variations is conducted using ground-based measurements of meteorological fields as well as chemical and aerosol species in Beijing, Shanghai and Guangzhou in January and July 2010. The meteorological datasets include surface temperature, wind speed and direction, relative humidity and precipitation. The chemical and aerosol species include $\mathrm{NOx}, \mathrm{O}_{3}, \mathrm{CO}, \mathrm{SO}_{2}, \mathrm{PM}_{2.5}$ and $\mathrm{PM}_{10}$. For a comprehensive model evaluation in each region, the following statistical indicators that provide complementary and valuable information on the model performance have been calculated: the mean bias (MB), the mean fractional bias (MFB), the mean fractional error (MFE), the root mean square error (RMSE), the correlation coefficient $(R)$ and the index of agreement (IOA). These validation metrics are described in many publications (Kang et al. 2006; Wilks, 2006; Willmott et al. 2012; Brasseur and Jacob, 2017) and are used in several model evaluation studies (e.g. Fu et al., 2012; Eskes et al., 2015) including the evaluation of the MACC European ensemble air quality forecasts (Marécal et al., 2015). They are computed using the following formulas:

$$
\begin{aligned}
M B & =\frac{1}{N} \sum_{i}\left(m_{i}-o_{i}\right) \\
M F B & =\frac{2}{N} \sum_{i} \frac{m_{i}-o_{i}}{m_{i}+o_{i}} \\
M F E & =\frac{2}{N} \sum_{i}\left|\frac{m_{i}-o_{i}}{m_{i}+o_{i}}\right| \\
R M S E & =\sqrt{\frac{1}{N} \sum_{i}\left(m_{i}-o_{i}\right)^{2}}
\end{aligned}
$$




$$
R=\frac{\overline{1} \sum_{i}\left(m_{i}-\bar{m}\right)\left(o_{i}-\bar{o}\right)}{\sigma_{m} \sigma_{o}}
$$

$$
I O A= \begin{cases}1-\frac{\sum_{i}\left|m_{i}-o_{i}\right|}{2 \sum_{i}\left|o_{i}-\bar{o}\right|}, & \text { if } \sum_{i}\left|m_{i}-o_{i}\right| \leq 2 \sum_{i}\left|o_{i}-\bar{o}\right| \\ \frac{2 \sum_{i}\left|o_{i}-\bar{o}\right|}{\sum_{i}\left|m_{i}-o_{i}\right|}-1, & \text { if } \sum_{i}\left|m_{i}-o_{i}\right|>2 \sum_{i}\left|o_{i}-\bar{o}\right|\end{cases}
$$

260

The ensemble $N$ consists of paired model and observed quantities $m_{i}$ and $o_{i}$, whose averages are $\bar{m}$ and $\bar{o}$ and standard deviations are $\sigma_{m}$ and $\sigma_{o}$.

\section{Meteorology evaluation}

Simulated daily mean surface temperature, wind speed and direction, relative humidity and precipitation are compared with surface observations made available within the PANDA project in the three considered cities. In Beijing, the temperature decreased to around $-15^{\circ} \mathrm{C}$ on the $5^{\text {th }}$ of January 2010 and started to increase afterwards but remained almost negative during the whole month of January. Only one moderate precipitation event $(1.7 \mathrm{~mm})$ was observed on the $3^{\text {rd }}$ of January (not shown), while the relative humidity exhibited a considerable temporal variability. Overall, WRF-Chem predicted temperature and relative humidity agree very well with the observations in Beijing in January 2010. During the month of July 2010, the observed temperature values exceeded $23{ }^{\circ} \mathrm{C}$ and the relative humidity remained around $70-80 \%$ except during the first week of July when it dropped to less than $40 \%$. WRF-Chem predicted temperature and relative humidity for July agree also very well with the observations although relative humidity is underestimated by around $10 \%$. The simulated pattern for wind speed agrees better with the observations in January than in July. The model tends however to overpredict the observed maximum values in Beijing.

The meteorological observations in Shanghai (Figure 3) show positive temperature values in January, being higher than in Beijing, and observed relative humidity varies between 40 to $90 \%$. In July, recorded temperature varies between $25^{\circ} \mathrm{C}$ and $33^{\circ} \mathrm{C}$ and relative humidity remained higher than $60 \%$. WRF-Chem predicted temperature and relative humidity agree very well with the observations in January. Predicted values in July 2010 are also in good agreement with the observations although 
283 simulated temperature is slightly lower by around 1 to $2^{\circ} \mathrm{C}$ and relative humidity is higher by around $28410 \%$ in the model during some specific days. As in Beijing, the model tends to overpredict maximum 285 mean wind speed by up to $2 \mathrm{~m} \mathrm{~s}^{-1}$ in January and $4 \mathrm{~m} \mathrm{~s}^{-1}$ in July 2010. The general pattern of the 286 simulated wind direction agrees well with the observations in January but a better agreement is found in 287 July 2010.
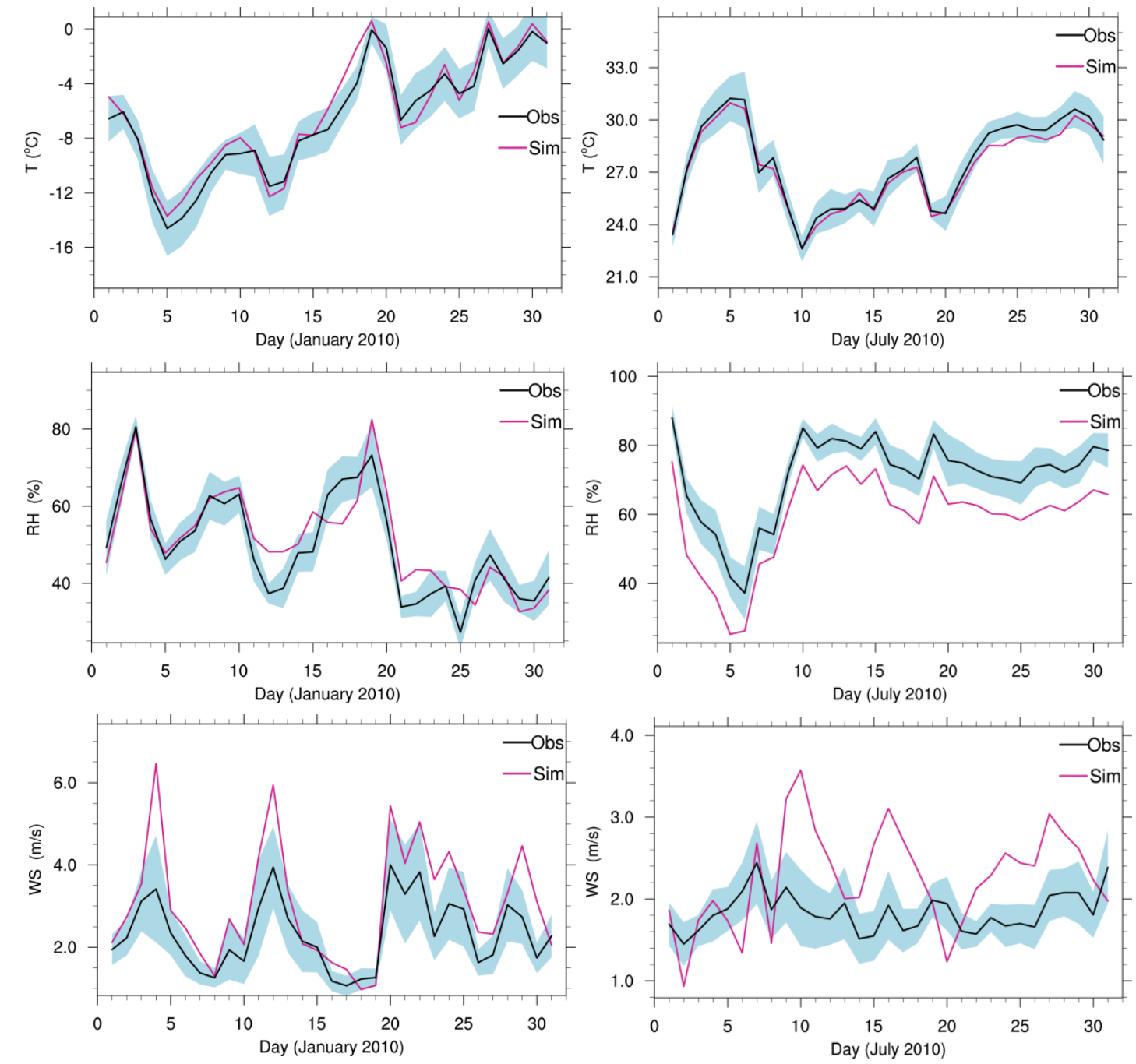

Figure 2: Time series of observed (black) and simulated (red) daily mean temperature (T), relative humidity (RH), wind speed (WS) in Beijing for January (left panels) and July (right panels) 2010. Standard deviations from the mean observations indicated with shaded area. 

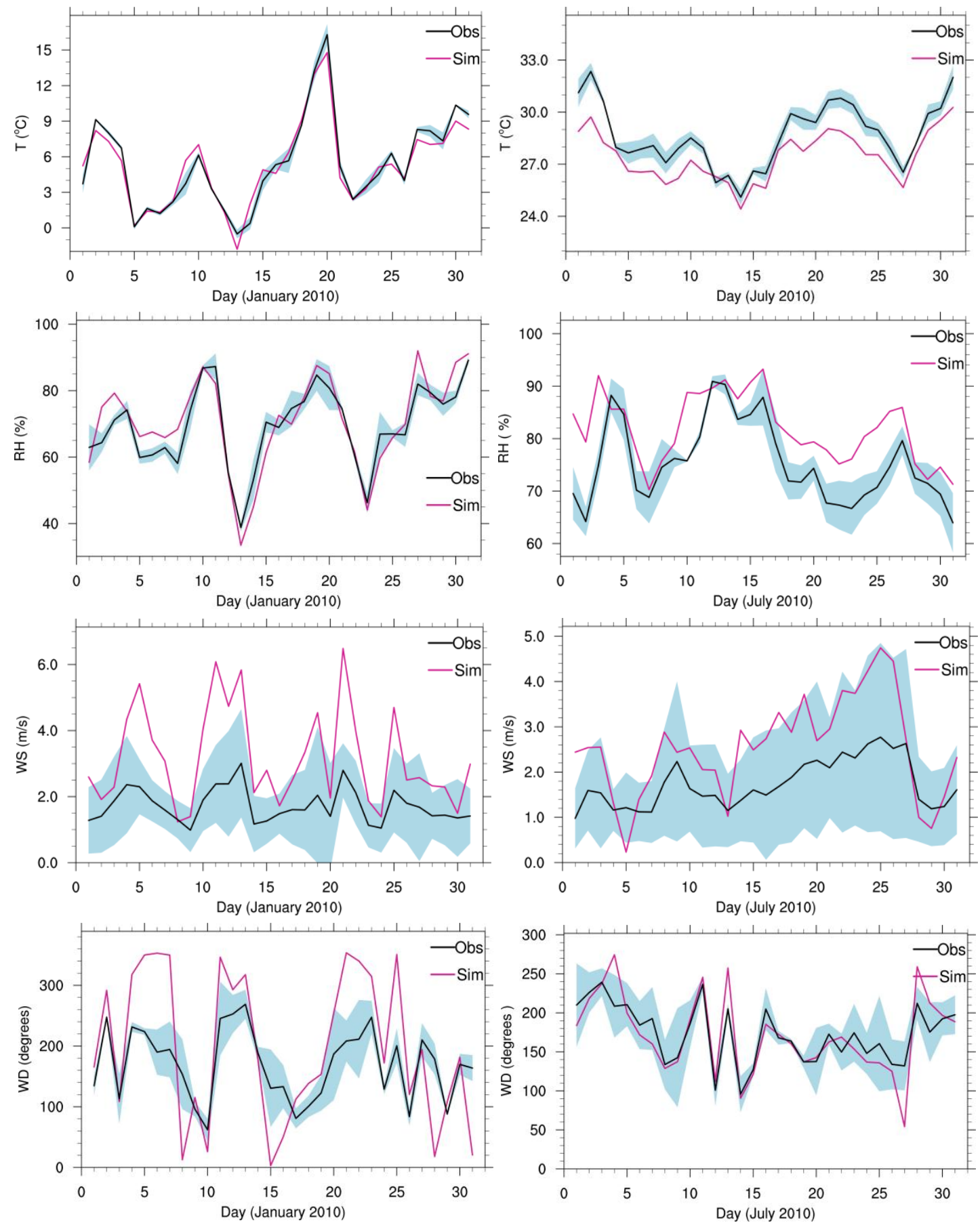

Figure 3: Time series of observed (black) and simulated (red) daily mean temperature (T), relative humidity (RH), wind speed (WS) and wind direction (WD) in Shanghai for January (left panels) and July (right panels) 2010. Standard deviations from the mean observations indicated with shaded area. 

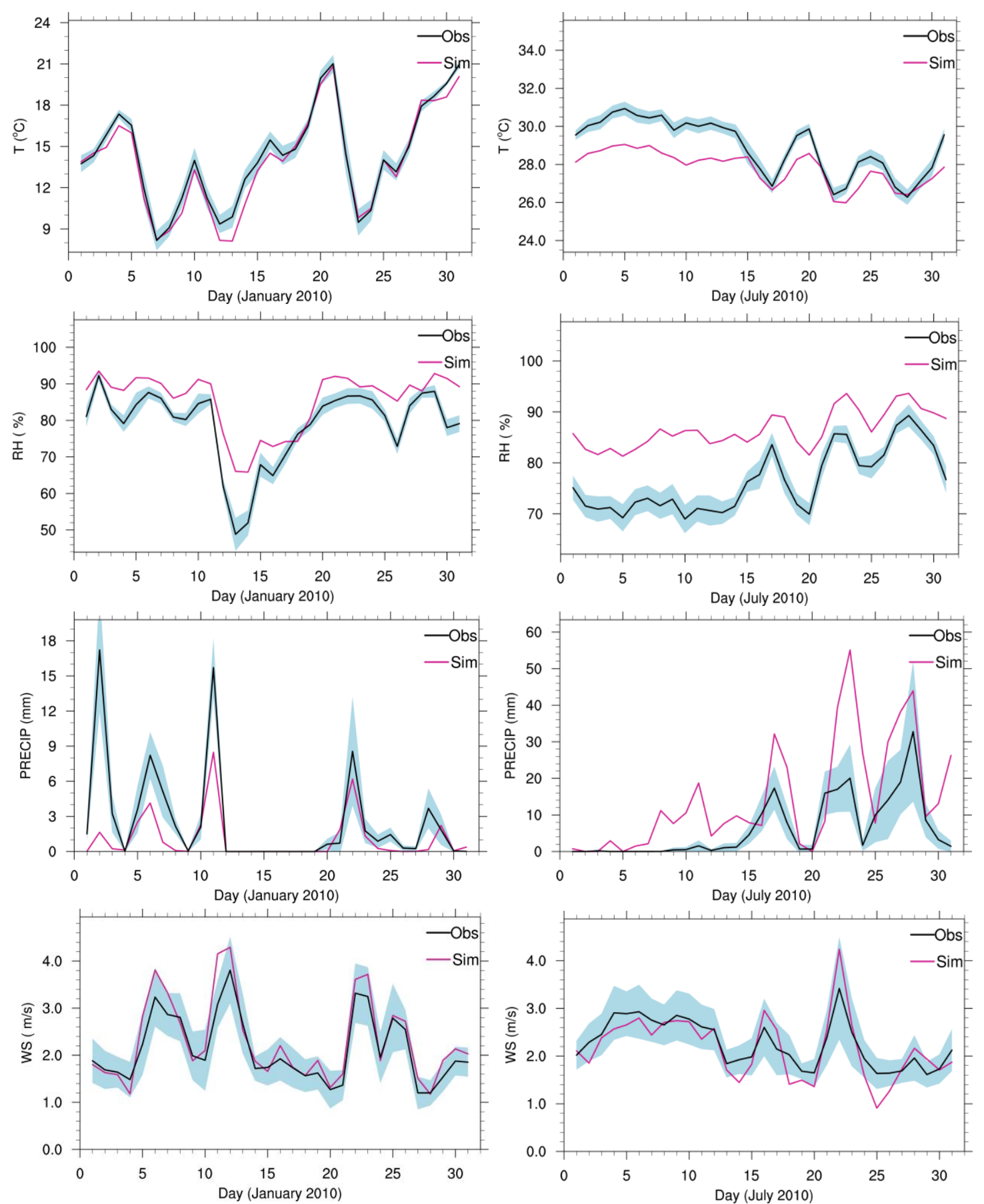

Figure 4: Time series of observed (black) and simulated (red) daily mean temperature (T), relative humidity $(\mathrm{RH})$, precipitation (PRECIP) and wind speed (WS) in Guangzhou for January (left panels) and July (right panels) 2010. Standard deviations from the mean observations indicated with shaded area. 
In Guangzhou, the observed variability of temperature, wind speed, temperature and relative humidity in January 2010 are well captured by the model (Figure 4). Predicted temperature is almost similar to the observations while wind speed and relative humidity are slightly higher (by around $1 \mathrm{~m} / \mathrm{s}$ and less than $15 \%$ respectively). The model captures nicely the precipitation events in January but observed peak values are underestimated. Predicted temperature and wind speed in July 2010 show also good agreement with observations although simulated temperature values are slightly lower. The model tends to overpredict both RH (+15\%) and precipitation (by 10-40 mm) in July 2010.

Overall, the WRF-Chem model setup used in the current study satisfactorily reproduces the meteorological situation in the three cities, allowing a better and confident analysis of the air quality model results discussed in the following sections. This is despite some overestimations of maximum values of surface wind speed which have also been reported in previous WRF-Chem modelling studies (Zhang et al. 2010; Tuccella et al. 2012; Zhang et al. 2015). Unresolved topographic features due to the smoother topography used in the model are among the possible reasons for the surface wind speed issue in WRF-Chem (Jiménez and Dudhia, 2012).

\section{Overview on the impact of emissions on model results}

In this section we compare first the three anthropogenic emission inventories HTAPv2, REASv2 and MACCity to assess their differences in both spatial distributions and magnitude of emissions. The three WRF-Chem simulations HTP, RAS and MCT, using separately these three different emission inventories are then analysed and compared with satellite measurements in order to assess the impact of anthropogenic emissions on air quality model predictions.

\subsection{Comparison of the anthropogenic emissions}

In order to quantify the differences between the inventories, averages of the emissions have been calculated over the domain D02 and also over three selected different city clusters, which include Beijing (the so-called Hebei-Beijing-Tianjin region), Shanghai (the Yangtze River Delta) and Guangzhou (the Perl River Delta). The Tables 1 and 2 show the HTAPv2 total emissions of CO, NO, $\mathrm{SO}_{2}, \mathrm{BC}$ and $\mathrm{OC}$ in January and July respectively, and the percentage differences between the HTAPv2 estimates and those of MACCity and REASv2. In January, HTAPv2 emissions are generally higher than those of MACCity in the domain D02 but lower estimates are found in some regions and for some 
species. For example, while HTAPv2 estimates are higher Beijing than those of MACCity, with large

403
Table 1: Total anthropogenic emissions in January in HTAPv2 in model domain D02 and in the Beijing, Shanghai and Guangzhou city-clusters and percentage differences with MACCity and REASv2.

\begin{tabular}{|c|l|r|r|r|r|r|}
\cline { 3 - 7 } \multicolumn{2}{c}{} & \multicolumn{1}{c|}{ CO } & \multicolumn{1}{c|}{ NO } & \multicolumn{1}{c|}{$\mathbf{S O}_{2}$} & \multicolumn{1}{c|}{ BC } & \multicolumn{1}{c|}{ OC } \\
\hline \multirow{3}{*}{ D02 } & HTAPv2 (Tg/month) & 21.3 & 1.6 & 2.64 & 0.23 & 0.54 \\
& HTAPv2-MACCity (\%) & 37 & 12 & -4.7 & 27.8 & 54.3 \\
& HTAPv2-REASv2 (\%) & -20.4 & -7 & -4.7 & 9.5 & 25.6 \\
\hline \multirow{3}{*}{ Beijing } & HTAPv2 (Tg/month) & 3.87 & 0.27 & 0.41 & 0.037 & 0.074 \\
& HTAPv2-MACCity (\%) & 98.5 & 35 & 7.9 & 60.9 & 85 \\
& HTAPv2-REASv2 (\%) & -28 & - & -6.8 & 15.6 & 34.5 \\
\hline \multirow{3}{*}{ Shanghai } & HTAPv2 (Tg/month) & 2.47 & 0.26 & 0.24 & 0.022 & 0.054 \\
& HTAPv2-MACCity (\%) & 17 & 30 & -40 & -15.4 & 10.2 \\
& HTAPv2-REASv2 (\%) & -39.8 & -10.3 & -17.2 & -18.5 & 8 \\
\hline \multirow{3}{*}{ Guangzhou } & HTAPv2 (Tg/month) & 0.7 & 0.086 & 0.12 & 0.006 & 0.016 \\
& HTAPv2-MACCity (\%) & -44 & -28 & -48 & -65 & -45 \\
& HTAPv2-REASv2 (\%) & -54.5 & -28 & -25 & -40 & -30 \\
\hline
\end{tabular}



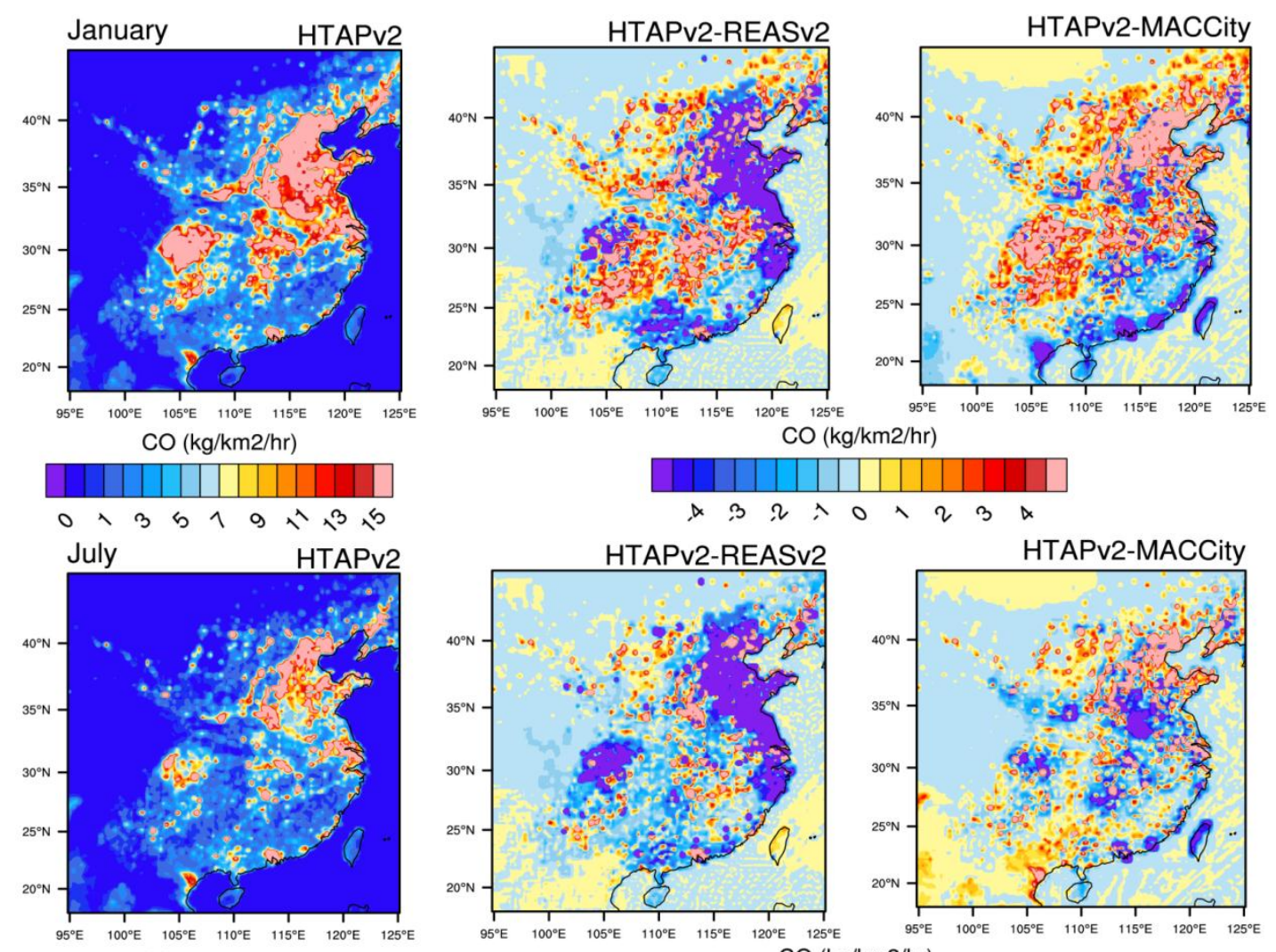

$\mathrm{CO}(\mathrm{kg} / \mathrm{km} 2 / \mathrm{hr})$
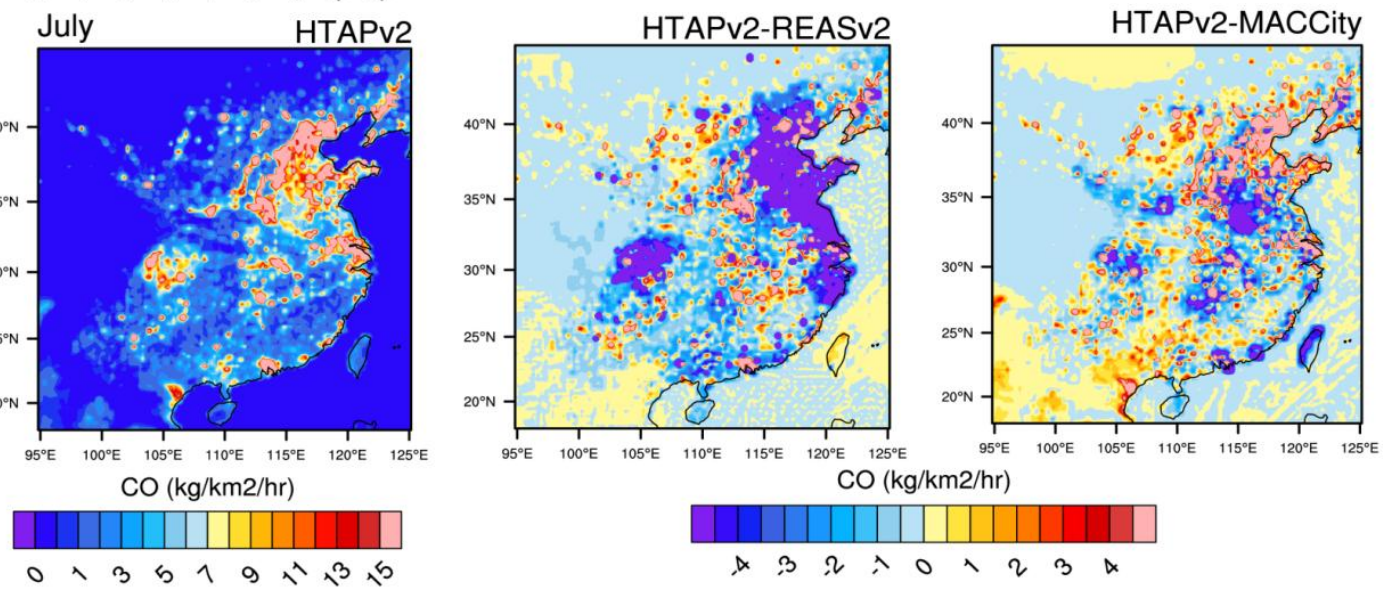

$\mathrm{CO}(\mathrm{kg} / \mathrm{km} 2 / \mathrm{hr})$

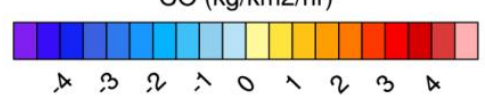

Figure 5: $\mathrm{CO}$ anthropogenic emissions $\left(\mathrm{Kg} / \mathrm{km}^{2} / \mathrm{hr}\right.$ ) in January (top panel) and July (bottom panel) in HTAPv2 and absolute differences with RASv2 and MACCity emissions.

441 In July, HTAPv2 estimates are also generally higher than those of MACCity in the domain D02 and in 442 Beijing, where differences of up to $78 \%, 86 \%$ and $42 \%$ are found in $\mathrm{CO}$, $\mathrm{NO}$ and $\mathrm{SO}_{2}$ emissions 443 respectively. HTAPv2 $\mathrm{CO}$ and NOx emissions are also higher than those of MACCity in Shanghai 444 (23\% and $80 \%$ respectively) but only moderate differences are found in Guangzhou. The larger 445 differences in this region are found in BC and OC emissions ( $-40 \%$ and $45 \%$ respectively). As in 446 January, HTAPv2 estimates are lower than those of REASv2 for many of species and large differences 447 are found in $\mathrm{CO}$ and $\mathrm{BC}$ emissions (e.g. $-53 \%$ and $-35 \%$ respectively in Shanghai). 
Table 2: Total anthropogenic emissions in July in HTAPv2 in model domain D02 and in the Beijing, Shanghai and Guangzhou city-clusters and percentage differences with MACCity and REASv2.

\begin{tabular}{|c|l|r|r|r|r|r|}
\cline { 3 - 7 } \multicolumn{1}{c}{} & \multicolumn{1}{c}{ CO } & \multicolumn{1}{c}{ NO } & \multicolumn{1}{c|}{ SO $_{2}$} & \multicolumn{1}{c|}{ BC } & \multicolumn{1}{c|}{ OC } \\
\hline \multirow{3}{*}{ D02 } & HTAPv2 (Tg/month) & 11.56 & 1.57 & 2.3 & 0.11 & 0.19 \\
& HTAPv2-MACCity (\%) & 19.2 & 42.7 & 24.2 & - & 35.7 \\
& HTAPv2-REASv2 (\%) & -40.9 & -7.1 & -14.8 & -21.4 & -9.5 \\
\hline \multirow{3}{*}{ Beijing } & HTAPv2 (Tg/month) & 2.2 & 0.28 & 0.37 & 0.018 & 0.024 \\
& HTAPv2-MACCity (\%) & 78.9 & 86.7 & 42.3 & 28.6 & 41.2 \\
& HTAPv2-REASv2 (\%) & -46.8 & 12 & -5.1 & -21.7 & -20 \\
\hline \multirow{3}{*}{ Shanghai } & HTAPv2 (Tg/month) & 1.55 & 0.27 & 0.26 & 0.013 & 0.02 \\
& HTAPv2-MACCity (\%) & 23 & 80 & -3.7 & -13.3 & 5.3 \\
& HTAPv2-REASv2 (\%) & -53.7 & -10 & -16.1 & -35 & -23.1 \\
\hline \multirow{3}{*}{ Guangzhou } & HTAPv2 (Tg/month) & 0.71 & 0.096 & 0.14 & 0.006 & 0.016 \\
& HTAPv2-MACCity (\%) & -5.3 & 6.7 & -6.7 & -40 & 45.5 \\
& HTAPv2-REASv2 (\%) & -40.8 & -12.7 & -12.5 & -25 & 6.7 \\
\hline
\end{tabular}

In order to illustrate differences in the spatial distributions of the emissions, Figures 5 and 6 display 462 monthly mean CO and NO emission fluxes in January and July from the HTAPv2 inventory and the 463 calculated absolute differences with REASv2 and MACCity. Consistent with the results in Tables 1 and 464 2, CO emissions in HTAPv2 are lower than in REASv2 in Beijing and the north-eastern regions in both 465 January and July. HTAPv2 exhibits also lower CO fluxes in the Sichuan Basin in July, but generally 466 higher estimates in central China in January. The HTAPv2 CO emissions are generally higher compared 467 to MACCity in central and northern China in January, but lower in the south-coastal regions. The 468 differences between HTAPv2 and REASv2 NO emissions at the regional scale are small, particularly in 469 January, but large discrepancies can be found in specific cities and local areas. Large differences 470 between HTAPv2 and MACCity NO emissions can be seen in several regions, in particular in the 471 northern and central regions of China.

472 Overall, the differences between the three inventories in terms of magnitude, resolution and spatial 473 distribution of the emissions are clearly visible at both the provincial and city scales. Large differences 474 are found over some specific areas such as the north-east region, the south coasts and central regions of 
China, in particular for some specific species (e.g. CO and NO). The magnitude of the differences

476 between the emissions estimates are not uniformly similar between January and July, and depend also on the species and regions considered. This indicates that in addition to differences in the resolution and spatial distribution of the emissions, there are also differences in their temporal variations.
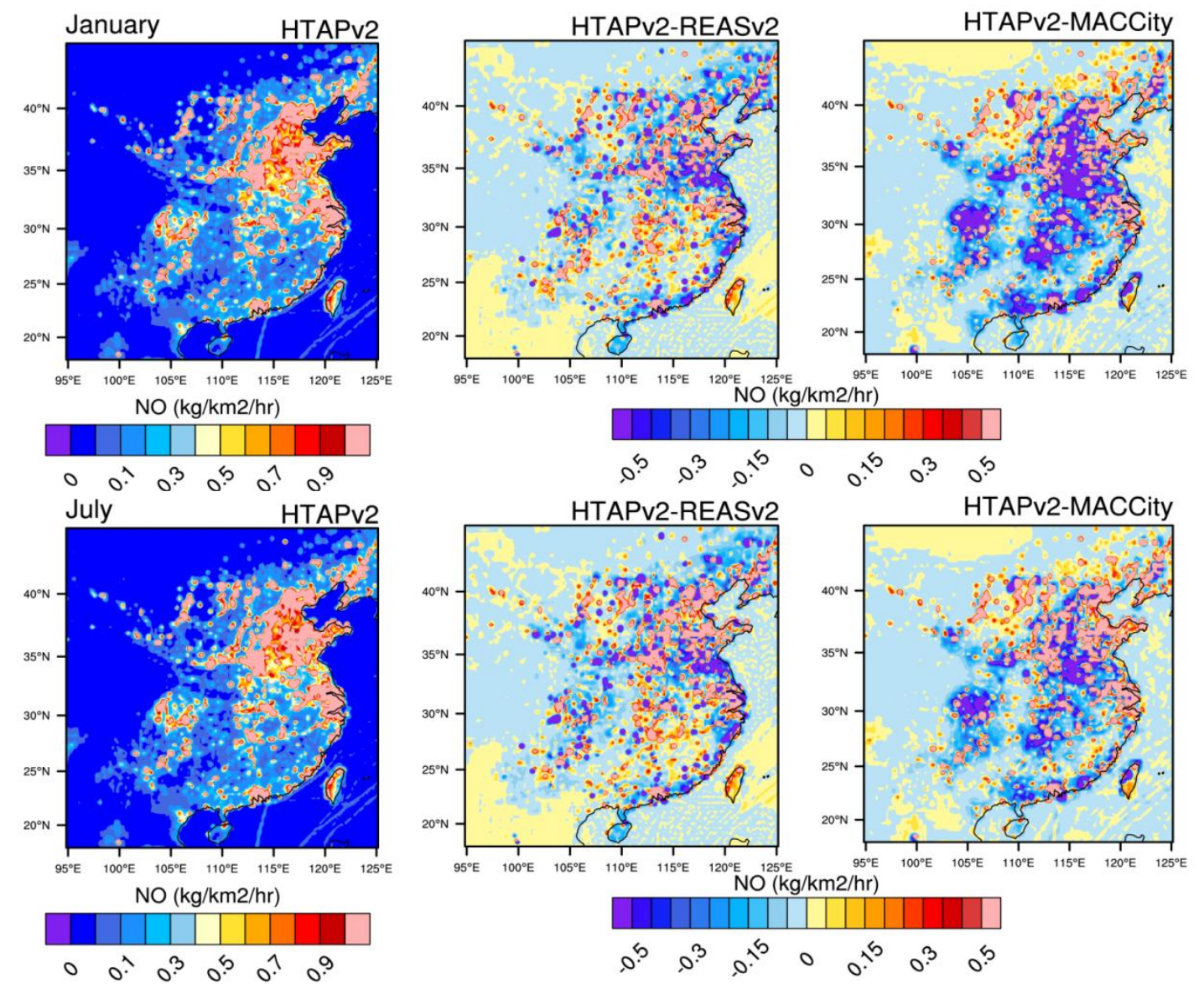

Figure 6: NO anthropogenic emissions $\left(\mathrm{Kg} / \mathrm{km}^{2} / \mathrm{hr}\right)$ in January (top panel) and July (bottom panel) in HTAPv2 and absolute differences with RASv2 and MACCity emissions.

\subsection{Effect of anthropogenic emissions on spatial distribution of pollutants}

In this section we compare the WRF-Chem simulations HTP, RAS and MCT, conducted separately with the HTAPv2, REASv2 and MACCity emissions respectively described in Section 2.3, to assess the changes in air quality model predictions related to the differences in the emissions. Figure 7 shows monthly mean surface mixing ratios of $\mathrm{CO}, \mathrm{NOx}$ and $\mathrm{O}_{3}$, and $\mathrm{PM}_{2.5}$ concentrations in January from the HTP simulation and absolute differences with RAS and MCT predictions. 


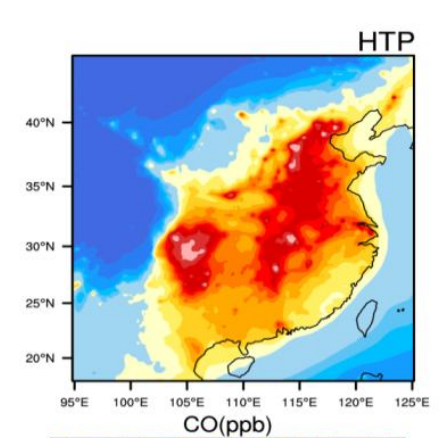

511
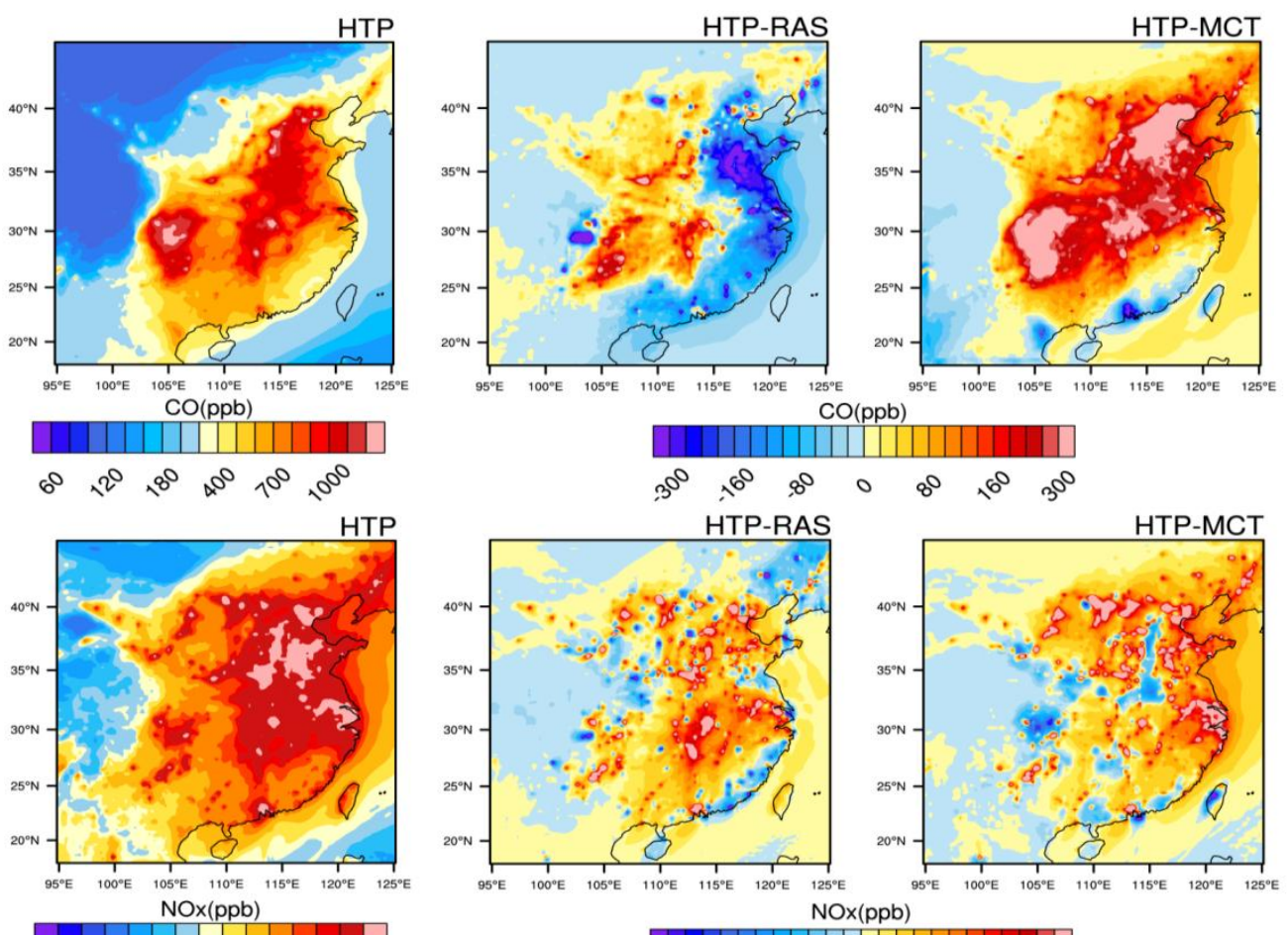

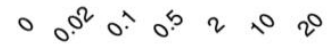
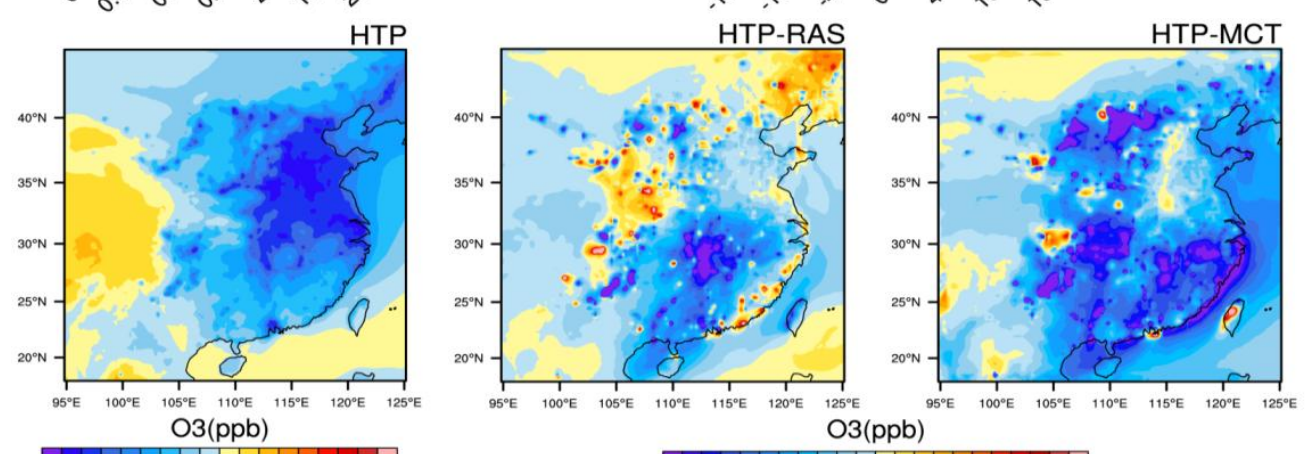

526
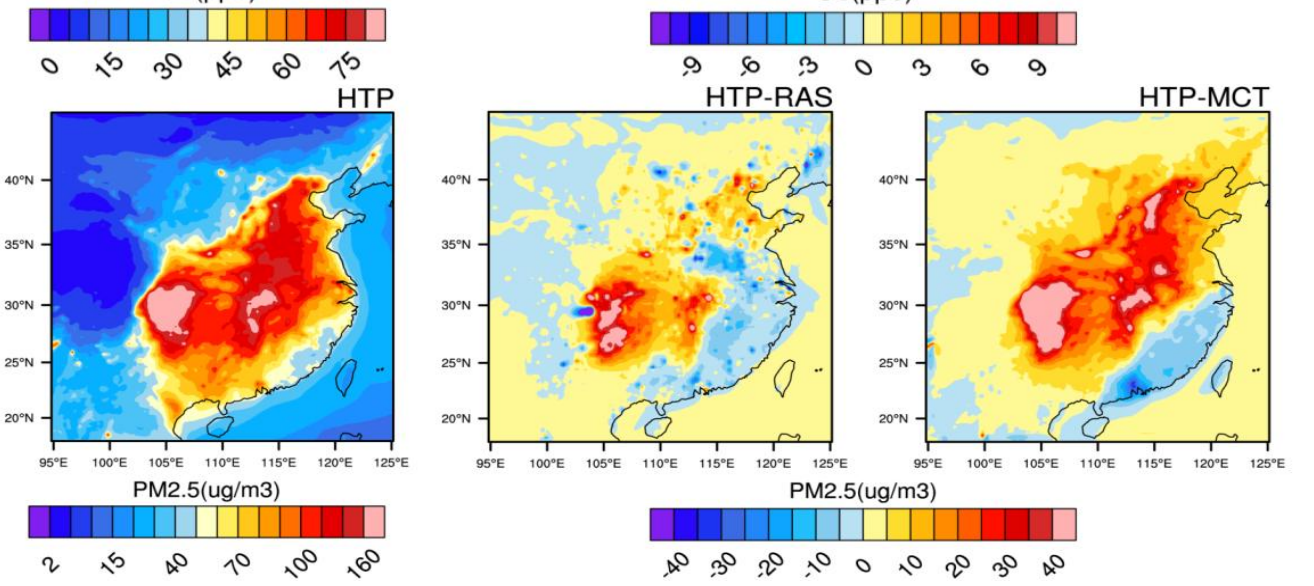

Figure 7: Monthly mean surface $\mathrm{CO}, \mathrm{NOx}, \mathrm{O}_{3}$ and $\mathrm{PM}_{2.5}$ surface concentrations simulated for January 2010 using HTAPv2 emissions (HTP) and absolute differences with model predictions with REASv2 (RAS) and MACCity (MCT) emissions. 
534 The most polluted regions in wintertime $\left(>1 \mathrm{ppm},>50 \mathrm{ppb}\right.$ and $>120 \mu \mathrm{g} \mathrm{m}^{-3}$ of CO, NOx and $\mathrm{PM}_{2.5}$ respectively) are located in north-eastern China, and in the Sichuan and Guangdong provinces, which are located in central and southern China respectively. Predicted CO concentrations for January are higher in RAS by more than 200 ppb compared to HTP in most of the north-eastern part of the country and around the coastal regions as a consequence of higher $\mathrm{CO}$ emissions in the REASv2 inventory (see Table 1). In central China however, HTP predicted higher concentration than RAS (over $100 \mathrm{ppb}$ ). This is again consistent with the differences in $\mathrm{CO}$ emissions identified between HTAPv2 and REASv2 inventories on Figure 5. In comparison to MCT, the HTP simulation shows higher CO values in most regions except in the Guangzhou region and other south coastal areas where MCT predicted CO concentrations higher by more than $150 \mathrm{ppb}$. This is also directly linked to differences in the emissions since, as indicated on Table 1 (see also Figure 5), HTAPv2 CO emissions estimates are higher than that of MACCity in Beijing and Shanghai regions, but lower in Guangzhou.

The general patterns of the differences in simulated NOx concentrations in January exhibit also similarities with those of the emissions. HTP predicted up to 10-15 ppb lower concentrations compared to RAS in the south coastal regions, but higher values in the central and northern regions. It predictsed also more than $15 \mathrm{ppb}$ higher NOx concentrations compared to MCT in most parts of China, particularly in the north-eastern regions. The predicted $\mathrm{O}_{3}$ concentrations over these regions are relatively low in January due to (1) low photochemical activity and (2) very high NOx concentrations, which does not favour the build-up of $\mathrm{O}_{3}$ due to titration effects. This could explain why HTP predicts lower $\mathrm{O}_{3}$ concentrations in general (by up to $10 \mathrm{ppb}$ ) compared to MCT over most regions. Similarly, differences in the predicted $\mathrm{O}_{3}$ between HTP and RAS could also be linked to differences in the predicted NOx concentrations.

In the case of $\mathrm{PM}_{2.5}$, HTP shows concentrations slightly lower by approximately $15 \mu \mathrm{g} \mathrm{m}^{-3}$ compared to MCT in Guangzhou and other southern parts of China due to lower BC and OC emissions in the HTAPv2 inventory (see Table 1). $\mathrm{PM}_{2.5}$ concentrations higher by more than $30 \mu \mathrm{g} \mathrm{m}^{-3}$ are simulated, however, in the Sichuan province in central China. The differences in $\mathrm{PM}_{2.5}$ between HTP and RAS do not exceed $15 \mu \mathrm{g} \mathrm{m}^{-3}$ in general in most regions except in the Sichuan province where HTP predicts higher concentrations by more than $30 \mu \mathrm{g} \mathrm{m}^{-3}$. 

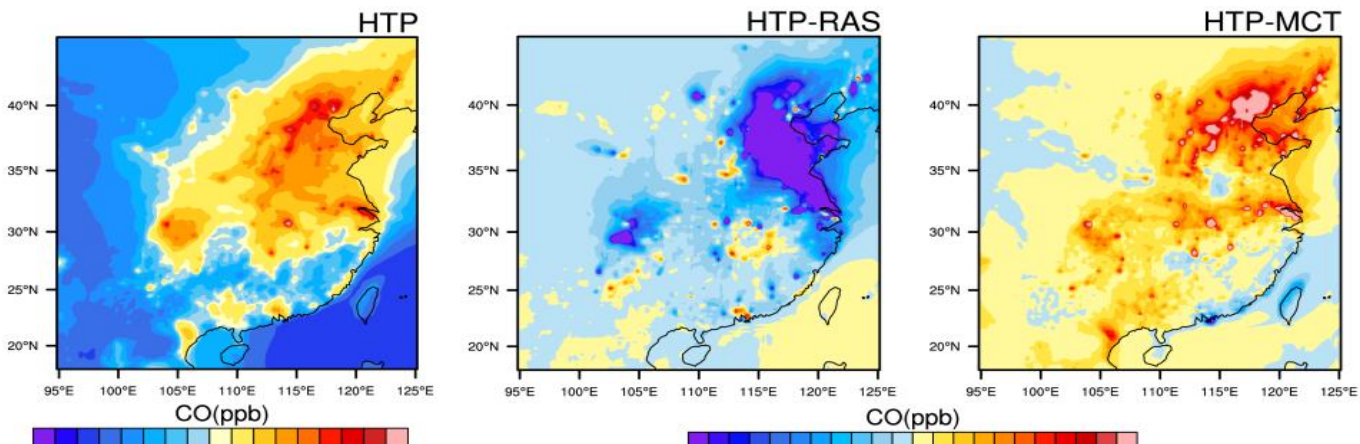

569

$N^{\circ} \quad 0^{\circ}, 6^{\circ} \quad 3^{\circ} \quad 6^{\circ}, 1^{\circ}$

HTP
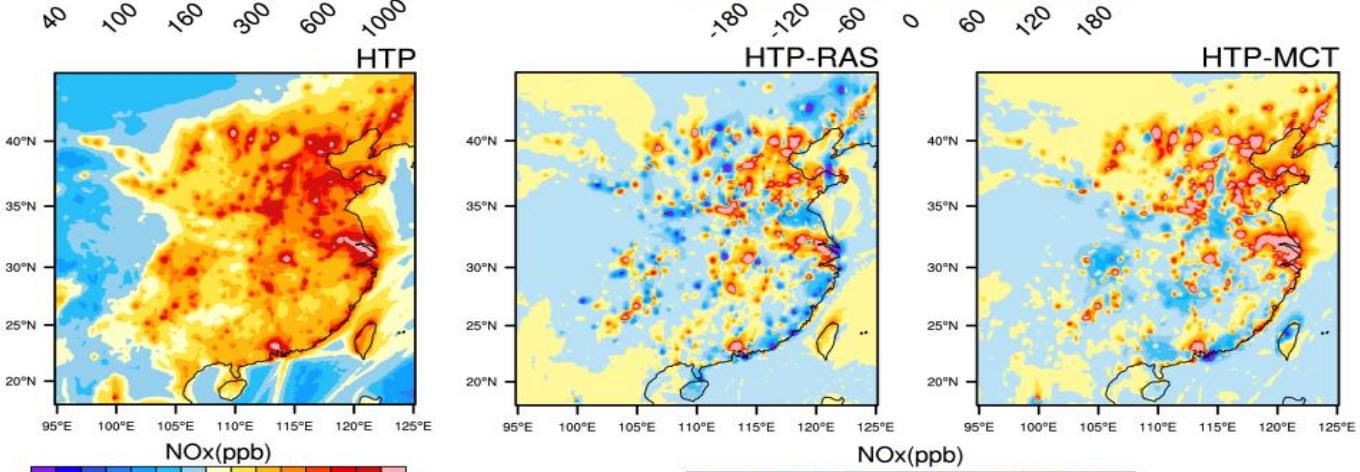

576

- $0^{2} 0.5 \%$

578

579

580

581

582

583

584

HTP
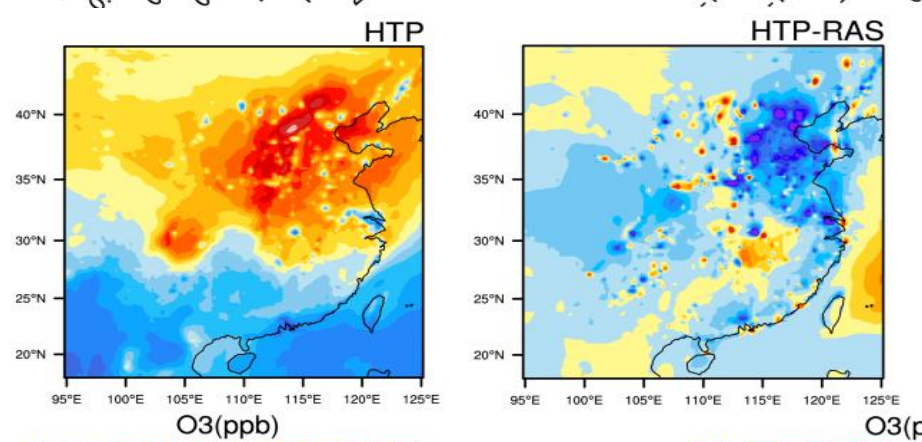

$\therefore>10$
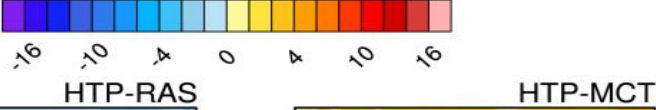

585

586

587

588

589

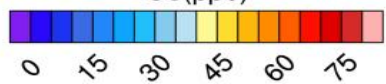

HTP
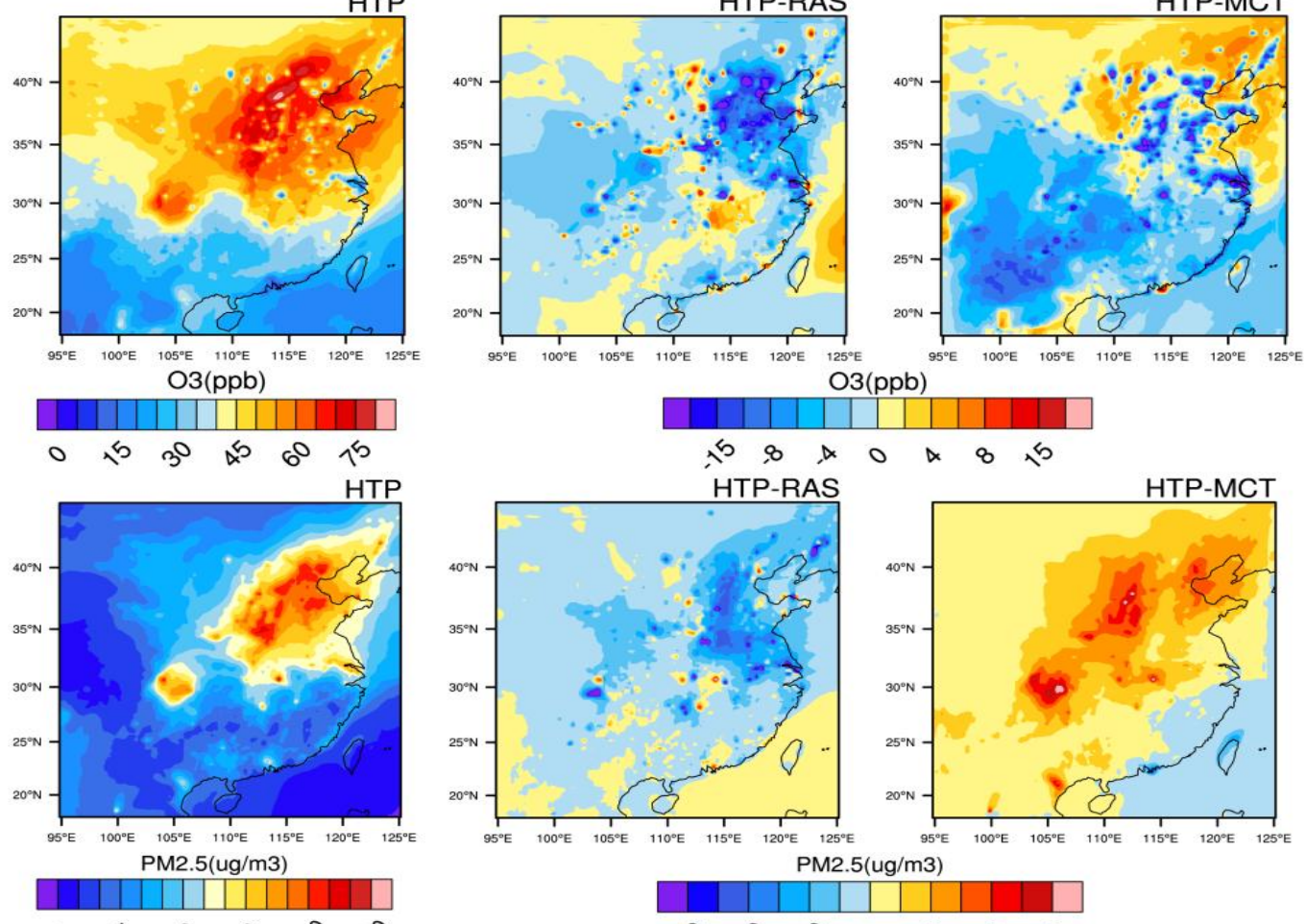

$\mathrm{O} 3(\mathrm{ppb})$

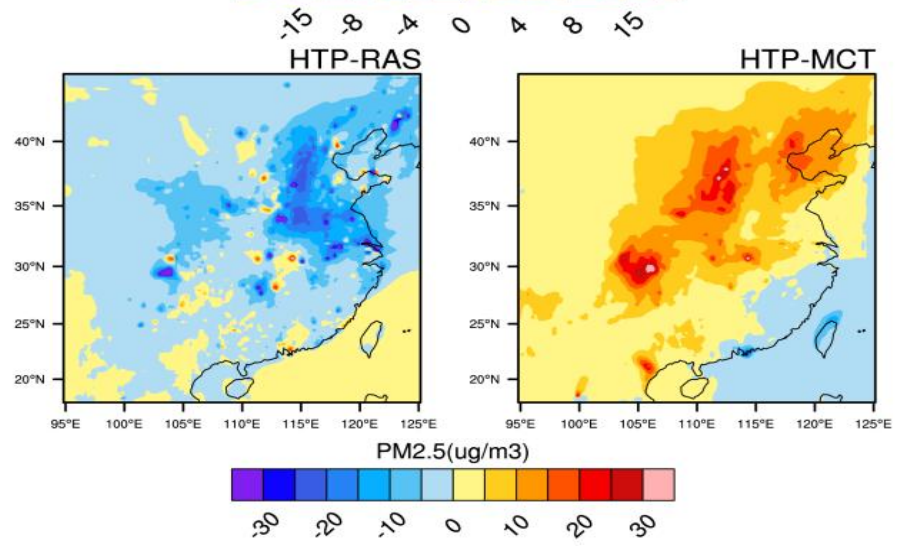

Figure 8: Monthly mean surface $\mathrm{CO}, \mathrm{NOx}, \mathrm{O}_{3}$ and $\mathrm{PM}_{2.5}$ surface concentrations model predictions with REASv2 (RAS) and MACCity (MCT) emissions. 
Figure 8 illustrates the results and differences for July 2010. The highest CO, NOx and $\mathrm{PM}_{2.5}$ concentrations are found mostly in the northern regions. Predicted concentrations are however lower ( $<500 \mathrm{ppb},<50 \mathrm{ppb}$ and $<100 \mu \mathrm{g} \mathrm{m}^{-3}$ respectively) compared to those in January due to a combination of lower emissions, increased photochemical activity during summer and increased precipitation due to the Asian monsoon, which increases the removal of soluble species. There are also clear similarities in the patterns of the differences between the simulations and those of the emissions in July. The HTP simulation predicts $\mathrm{CO}$ and NOx concentrations that are higher by more than $100 \mathrm{ppb}$ and $10 \mathrm{ppb}$ respectively compared to MCT in the north-eastern regions. HTP shows also higher NOx compared to RAS over the north-eastern regions but lower CO concentrations (by more than $15 \mathrm{ppb}$ and less than $200 \mathrm{ppb}$ respectively). This is also consistent with the differences between HTAPv2 and REASv2 concerning the $\mathrm{NO}$ and $\mathrm{CO}$ emissions as indicated on Figures 5 and 6 respectively. The differences in $\mathrm{O}_{3}$ between the simulations do not exceed $10 \mathrm{ppb}$ in most regions in general, but higher differences of more than $15 \mathrm{ppb}$ can be found in some specific regions such as Beijing and Shanghai and surrounding areas. The HTP simulation shows $\mathrm{PM}_{2.5}$ concentrations up to $20 \mu \mathrm{g} \mathrm{m}^{-3}$ lower than RAS in the northern regions, but over $20 \mu \mathrm{g} \mathrm{m}^{-3}$ higher values compared to MCT. Again, these discrepancies could be related to the differences between the emissions estimates such as for BC and OC.

\subsection{Comparison with satellite observations}

The spatial distribution of pollutants and the effects of anthropogenic emissions are also assessed in this section by comparing results of the three model simulations HTP, RAS and MCT with MOPITTv6 and GOME2 satellite observations. Comparisons of the simulated CO total columns for January and July 2010 against MOPITTv6 CO retrievals are shown on Figure 9. For an appropriate comparison, modeled $\mathrm{CO}$ concentrations are transformed by the MOPITTv6 averaging kernels and a priori $\mathrm{CO}$ profiles. Details on the method of calculation can be found in Wagner et al. (2015) and references therein.

In general, the HTP and RAS simulations exhibit almost similar CO distributions in January and higher concentrations than MCT due to higher $\mathrm{CO}$ emissions in the HTAPv2 and REASv2 inventories compared to MACCity as discussed in Sect. 4.1 (see also Table 1). The model simulations are generally consistent with MOPITTv6 observations, capturing correctly the spatial patterns of CO total columns, and the high values in eastern China and in the Sichuan basin. There are however some differences with MOPITTv6 regarding the magnitude of CO total columns. 
624

625

626

627

628

629

630

631

632

633

634

635

636

637

638

639

640

641

642

643

644

645

646

647

648

649

650

651

652

653
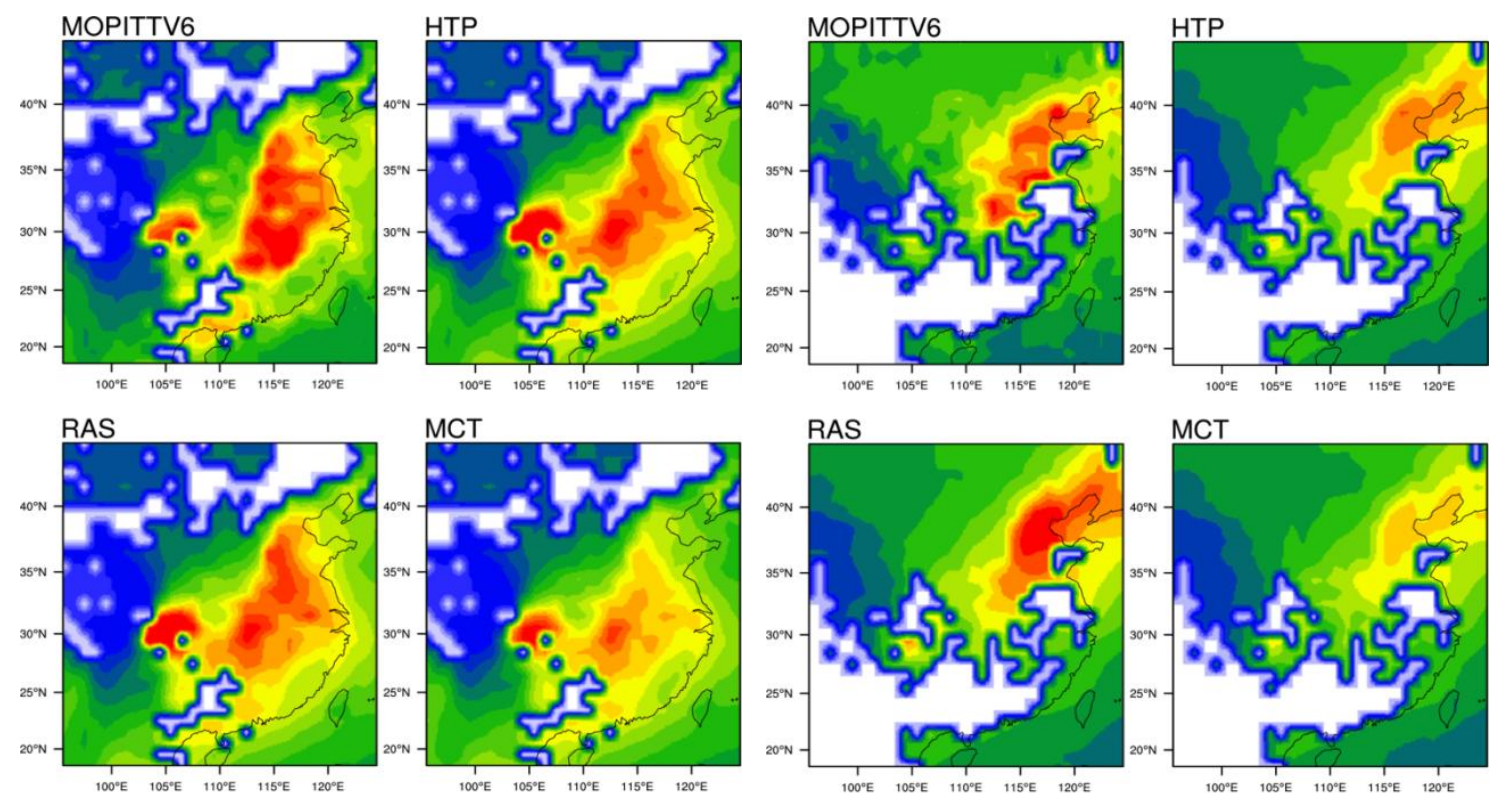

$\mathrm{CO}$ (x $1 . e 18$ molec.cm-2)
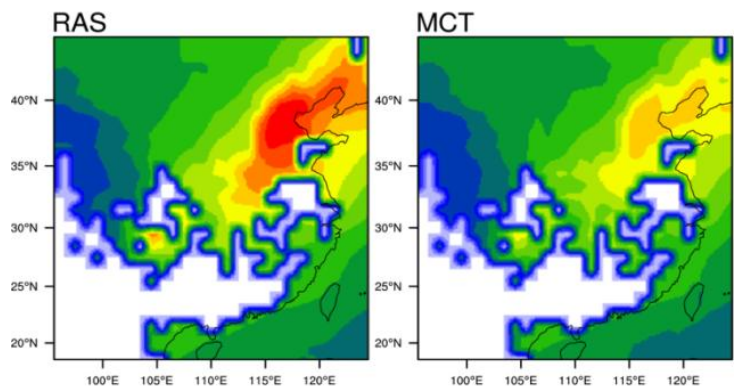

$\mathrm{CO}$ (x 1.e18 molec.cm-2)
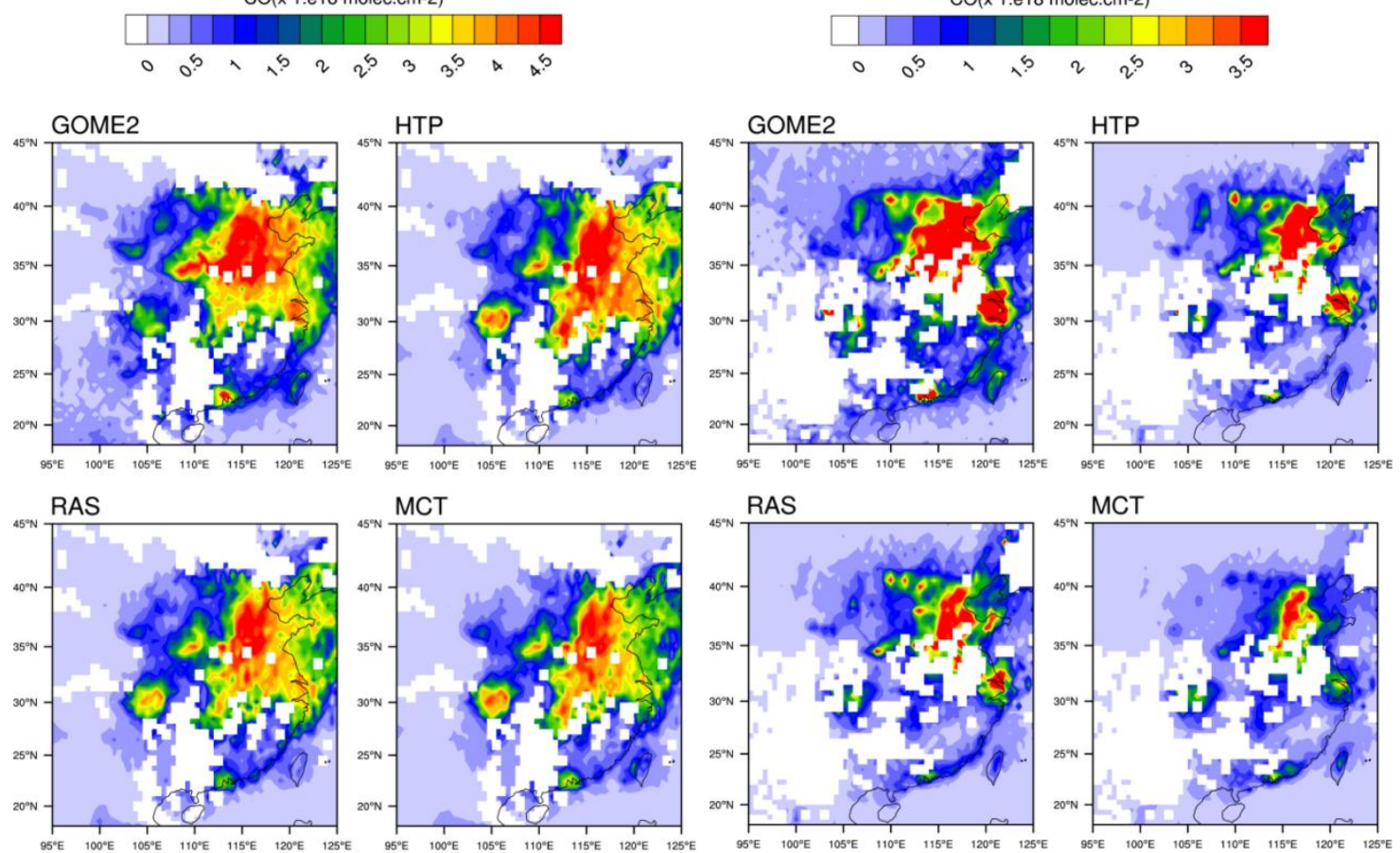

$\mathrm{NO} 2(\times 1 . e 15$ molec.cm-2)
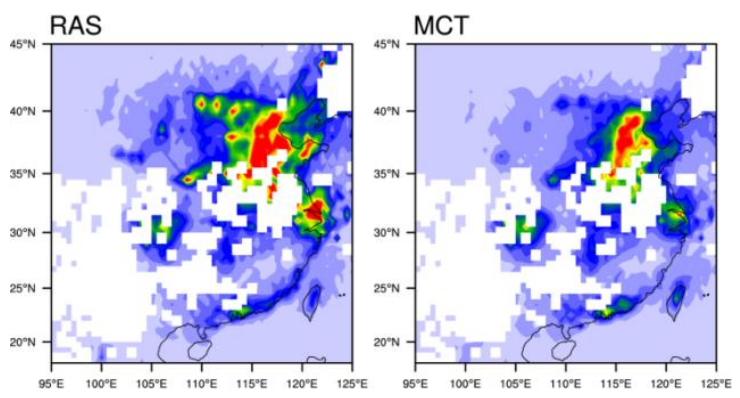

NO2 (x 1.e15 molec.cm-2)

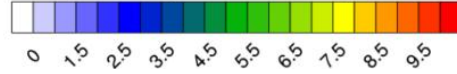

Figure 9: Comparison of predicted CO total columns and $\mathrm{NO}_{2}$ tropospheric columns in January (left panels) and July 2010 (right panels) with the three emissions inventories against MOPITTv6 and GOME2 observations, respectively. 
All the simulations tend to underestimate the high CO concentrations in eastern China in January although RAS and HTP show higher values over the Sichuan province compared to MOPITTv6. Comparisons with surface CO measurements in the Beijing region discussed in Sect. 5.1 also lead to the same conclusion of CO underestimation in the simulations in January 2010, although observations are available only at one station. Underestimation of wintertime CO emissions in some eastern China provinces in the current inventories could be a possible explanation for the $\mathrm{CO}$ underestimation in the model simulations. Stein et al. (2014) pointed also to possible overestimation of CO sinks (e.g. dry deposition) in most state-of-the-art chemistry transport models, which can lead the negative CO bias in the northern hemisphere during winter.

The regions of high CO concentrations in July 2010 are located in north-eastern China, especially in the Beijing region, while the southern regions, influenced by the summer Asian monsoon, show lower CO concentrations. The general spatial pattern of $\mathrm{CO}$ total columns in July is well captured by the simulations, which show however significant magnitude differences related to the differences between the applied emissions. Predicted CO values in July are higher in RAS than in HTP, while the MCT simulation exhibits lower CO total columns and clear underestimation in the Beijing region. This is also consistent with results of the comparison of $\mathrm{CO}$ emissions displayed on Table 2, which indicate $\mathrm{CO}$ amounts in Beijing in MACCity lower by $78 \%$ compared to HTAPv2.

Comparison of the predicted monthly mean $\mathrm{NO}_{2}$ tropospheric columns with GOME2 observations are displayed on Figure 9. For a proper comparison, simulated $\mathrm{NO}_{2}$ distributions are transformed using the GOME2 averaging kernels following Eskes and Boersma (2003). Due to the short $\mathrm{NO}_{2}$ lifetime, its high concentrations are generally correlated with high emissions areas, which are mostly located in the north-eastern regions such as Beijing but also in the Shanghai and Guangzhou regions and in the Sichuan basin. Overall, the spatial patterns of tropospheric $\mathrm{NO}_{2}$ columns in January 2010 are reproduced reasonably by all the simulations. The $\mathrm{NO}_{2}$ values in the north-eastern regions are however better captured by HTP compared in particular to the MCT simulation. This is consistent with the results discussed in Sect. 5.1, which show a better agreement of HTP with surface NOx measurements in the Beijing region in January 2010 compared to other simulations (see also Figure 10). All the simulations underestimate $\mathrm{NO}_{2}$ tropospheric columns in the Guangzhou region, consistent also with the results discussed in Sect. 5.1 (see also Figure 13), but show overestimations in the Sichuan basin. GOME2 observations for July 2010 show a broader region of high $\mathrm{NO}_{2}$ tropospheric columns in north 
eastern China compared to the model predictions. HTP shows slightly better agreement with GOM2 , while MCT shows much lower concentrations and higher underestimation, which is linked to the lower NO emissions in MACCity (Table2).

The discrepancies found between the simulations and MOPITT and GOME2 observations should not completely incriminate the model performance or the emissions used. It could also be due to uncertainties in satellite retrievals. For example, previous studies have shown that significant uncertainties in $\mathrm{NO}_{2}$ satellite observations could result from the different assumptions used in the retrievals calculations, such as the cloud mask applied, airmass factors, the stratosphere-troposphere separation, and system errors due to surface reflectivity and aerosols (Richter and Burrows, 2002; Martin et al., 2002; Boersma et al. 2004). The relative errors can reach $40-60 \%$ in polluted areas of China (Ma et al, 2006; Boersma et al. 2004), indicating that careful interpretation is required in quantitative model evaluation with satellite measurements.

\section{Evaluation against surface measurements}

\subsection{Evaluation with surface observations in January 2010}

Figure 10 illustrates time series of simulated and observed surface concentrations of $\mathrm{NOx}, \mathrm{O}_{3}, \mathrm{CO}_{2} \mathrm{SO}_{2}$, $\mathrm{PM}_{2.5}$ and $\mathrm{PM}_{10}$ in Beijing in January 2010. The three model simulations HTP, RAS and MCT replicate correctly the variability of all observed species and capture the increase of concentrations during two pollution episodes that occurred during the second and third week of January 2010. The statistical indicators displayed in Table 3 confirm the good agreement between all the simulations and the observations, with IOA and $\mathrm{R}$ values higher than 0.5 and 0.6 , respectively, for most of the species. The simulations meet also the performance goals for particulates (MFB and MFE limits of \pm 0.3 and 0.5 , respectively) as recommended by Boylan and Russel (2006). The HTP simulation captures however better than RAS and MCT the peak concentrations of NOx and particulates during the two pollution events in January 2010. In terms of bias, HTP produces also lower MB and MFB values for NOx, $\mathrm{SO}_{2}$ and $\mathrm{PM}_{10}$, while MCT exhibits higher biases in general compared to the two other simulations. Low $\mathrm{O}_{3}$ concentrations are observed in Beijing in January and the model simulations exhibit comparable performances with small $\mathrm{MB}$ and $\mathrm{MFB}$, good correlation $(\mathrm{R}>0.6)$ and a good index of agreement $(\mathrm{IOA}>0.52)$. All model simulations tend to underestimate $\mathrm{CO}$ concentrations in the unique $\mathrm{CO}$ measurement site in Beijing. The peak CO concentrations observed during the two pollution episodes in 
January (3.5 and 6 ppm respectively) are underpredicted by more than $50 \%$ with the highest bias found in MCT due most likely to lower CO anthropogenic emissions in the MACCity inventory as discussed in Section 4.1 .

Table 3: Statistical skills in Beijing, Shanghai and Guangzhou in January 2010 with the HTP (left columns), RAS (center columns) and MCT (right columns) model simulations.

\begin{tabular}{l|rrr|rrr|rrr|rrr|rrr}
\hline Beijing & \multicolumn{3}{|c|}{ NOx } & \multicolumn{3}{|c|}{$\mathbf{O}_{\mathbf{3}}$} & \multicolumn{3}{|c|}{$\mathbf{S O}_{\mathbf{2}}$} & \multicolumn{3}{|c|}{$\mathbf{P M}_{\mathbf{2 . 5}}$} & \multicolumn{3}{|c}{$\mathbf{P M}_{\mathbf{1 0}}$} \\
\hline MB & 6.3 & -19.4 & -25.3 & -3.7 & -1.5 & 1.1 & -9.5 & -13.2 & -17.6 & 17.1 & 0.11 & -12.6 & -31.1 & -35.5 & -61.9 \\
MFB & 0.10 & -0.25 & -0.45 & -0.49 & -0.16 & 0.04 & -0.21 & -0.28 & -0.38 & 0.28 & 0.17 & 0.04 & -0.23 & -0.24 & -0.44 \\
MFE & 0.44 & 0.58 & 0.70 & 0.67 & 0.50 & 0.55 & 0.57 & 0.52 & 0.64 & 0.51 & 0.43 & 0.45 & 0.43 & 0.41 & 0.52 \\
RMSE & 44.8 & 41.1 & 44.8 & 6.96 & 6.61 & 8.22 & 31.1 & 28.6 & 34.8 & 72.1 & 64.8 & 70.1 & 84.7 & 80.4 & 97.1 \\
R & 0.60 & 0.65 & 0.63 & 0.75 & 0.70 & 0.59 & 0.59 & 0.70 & 0.54 & 0.69 & 0.72 & 0.67 & 0.68 & 0.72 & 0.67 \\
IOA & 0.52 & 0.58 & 0.53 & 0.60 & 0.63 & 0.52 & 0.59 & 0.63 & 0.55 & 0.64 & 0.72 & 0.71 & 0.61 & 0.62 & 0.54 \\
\hline
\end{tabular}

\begin{tabular}{l|rrr|rrr|rrr|rrr}
\hline Shanghai & \multicolumn{3}{|c|}{ NOx } & \multicolumn{3}{c|}{$\mathbf{O}_{\mathbf{3}}$} & \multicolumn{3}{|c|}{$\mathbf{P M}_{\mathbf{2 . 5}}$} & \multicolumn{3}{c}{ PM $_{\mathbf{1 0}}$} \\
\hline MB & 31.6 & 64.1 & -19.8 & -5.3 & -6.8 & 2.4 & 1.5 & 5.1 & 4.4 & -4.8 & 13.7 & -2.1 \\
MFB & 0.26 & 0.57 & -0.51 & -0.68 & -1.0 & 0.14 & -0.08 & -0.07 & -0.03 & -0.13 & 0.03 & -0.09 \\
MFE & 0.54 & 0.65 & 0.65 & 0.73 & 1.0 & 0.74 & 0.32 & 0.37 & 0.33 & 0.34 & 0.33 & 0.33 \\
RMSE & 63.5 & 98.9 & 35.5 & 9.18 & 10.3 & 8.38 & 32.0 & 41.8 & 35.1 & 42.1 & 61.7 & 44.8 \\
R & 0.60 & 0.50 & 0.59 & 0.65 & 0.62 & 0.68 & 0.79 & 0.76 & 0.77 & 0.75 & 0.73 & 0.74 \\
IOA & 0.14 & -0.26 & 0.45 & 0.61 & 0.56 & 0.63 & 0.63 & 0.55 & 0.61 & 0.63 & 0.54 & 0.62 \\
\hline
\end{tabular}

\begin{tabular}{l|rrr|rrr|rr|rr|rrr|rrr}
\hline Guangzhou & \multicolumn{3}{|c|}{$\mathbf{N O}_{\mathbf{2}}$} & \multicolumn{3}{|c|}{$\mathbf{O}_{\mathbf{3}}$} & \multicolumn{3}{|c|}{$\mathbf{S O}_{\mathbf{2}}$} & \multicolumn{3}{|c|}{$\mathbf{P M}_{\mathbf{2 . 5}}$} & \multicolumn{3}{|c}{$\mathbf{P M}_{\mathbf{1 0}}$} \\
\hline MB & -4.3 & -6.3 & -4.4 & -14.4 & -10.7 & -8.4 & 6.6 & 0.8 & 7.4 & 17.2 & 22.8 & 37.1 & -0.8 & 10.5 & 21.6 \\
MFB & -0.11 & -0.19 & -0.12 & -0.63 & -0.32 & -0.20 & 0.29 & 0.11 & 0.33 & 0.34 & 0.42 & 0.60 & 0.10 & 0.20 & 0.29 \\
MFE & 0.47 & 0.45 & 0.48 & 0.65 & 0.47 & 0.42 & 0.33 & 0.22 & 0.36 & 0.51 & 0.52 & 0.61 & 0.53 & 0.53 & 0.54 \\
RMSE & 19.7 & 18.3 & 19.7 & 19.3 & 17.1 & 15.7 & 13.2 & 4.9 & 9.7 & 35.6 & 38.8 & 48.6 & 54.5 & 55.3 & 55.5 \\
R & 0.51 & 0.66 & 0.64 & 0.36 & 0.37 & 0.30 & 0.48 & 0.68 & 0.51 & -0.06 & -0.09 & 0.08 & -0.09 & -0.02 & -0.01 \\
IOA & 0.45 & 0.47 & 0.46 & 0.48 & 0.52 & 0.50 & 0.22 & 0.51 & 0.28 & 0.23 & 0.16 & -0.08 & 0.41 & 0.39 & 0.36 \\
\hline
\end{tabular}

We present in this section an analysis of the major pollution episode that occurred on 15-20 January in north-eastern China. As displayed on Figure 10, $\mathrm{NOx}, \mathrm{CO}, \mathrm{SO}_{2}, \mathrm{PM}_{2.5}$ and $\mathrm{PM}_{10}$ concentrations reached the extremely high values of $150 \mathrm{ppb}, 6 \mathrm{ppm}, 80 \mathrm{ppb}, 300 \mu \mathrm{g} \mathrm{m}^{-3}$ and $400 \mu \mathrm{g} \mathrm{m}^{-3}$, respectively on 18 January 2010. During this pollution episode, the wind speed measurements in Beijing (see Figure 2) decreased to less than $1 \mathrm{~m} \mathrm{~s}^{-1}$ indicating air stagnation and thus accumulation of pollutants in the lower troposphere. Analysis of the modeled vertical distribution of temperature (Figure 11) shows a positive gradient in the layer $200 \mathrm{~m}$ to $1.4 \mathrm{~km}$ and an inversion layer below $200 \mathrm{~m}$. Such conditions reduce the vertical mixing and lead to the build-up of primary pollutants in the boundary layer. The relative 
732 humidity increased to up to $70 \%$ during this pollution episode (see Figure 2). This moist atmosphere

733 situation may have led also to the formation of secondary pollutants. The increase in NOx

734 concentrations combined with high aerosol loading, which can decrease the photochemical activity due

735 to low radiation, could explain the observed high ozone loss during this pollution event. As discussed in

736 Section 3, the model reproduces relatively well the meteorological situation in Beijing in January 2010.

737 This explains the good performance of the model simulations during this particular pollution event. The

738 moderate pollution event that occurred in the second week of January could also be due to stable

739 meteorological situation with low wind speed values as indicated on Figure 2.

740
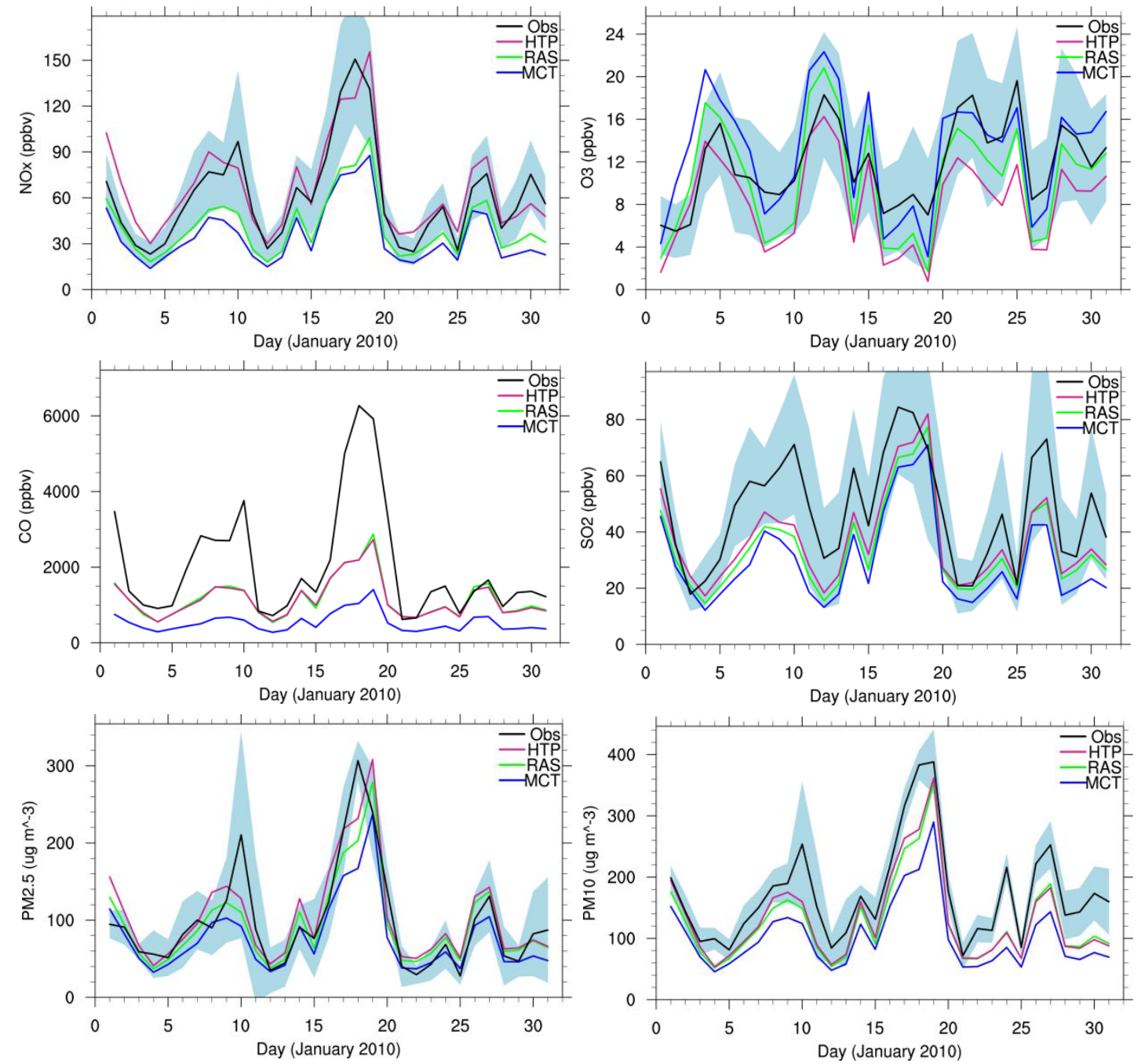

Figure 10: Time series of observed and simulated daily mean concentrations of NOx, $\mathrm{O}_{3}, \mathrm{CO}, \mathrm{SO}_{2}, \mathrm{PM}_{2.5}$ and $\mathrm{PM}_{10}$ in Beijing for January 2010. Standard deviations from the mean observations indicated with shaded area. 

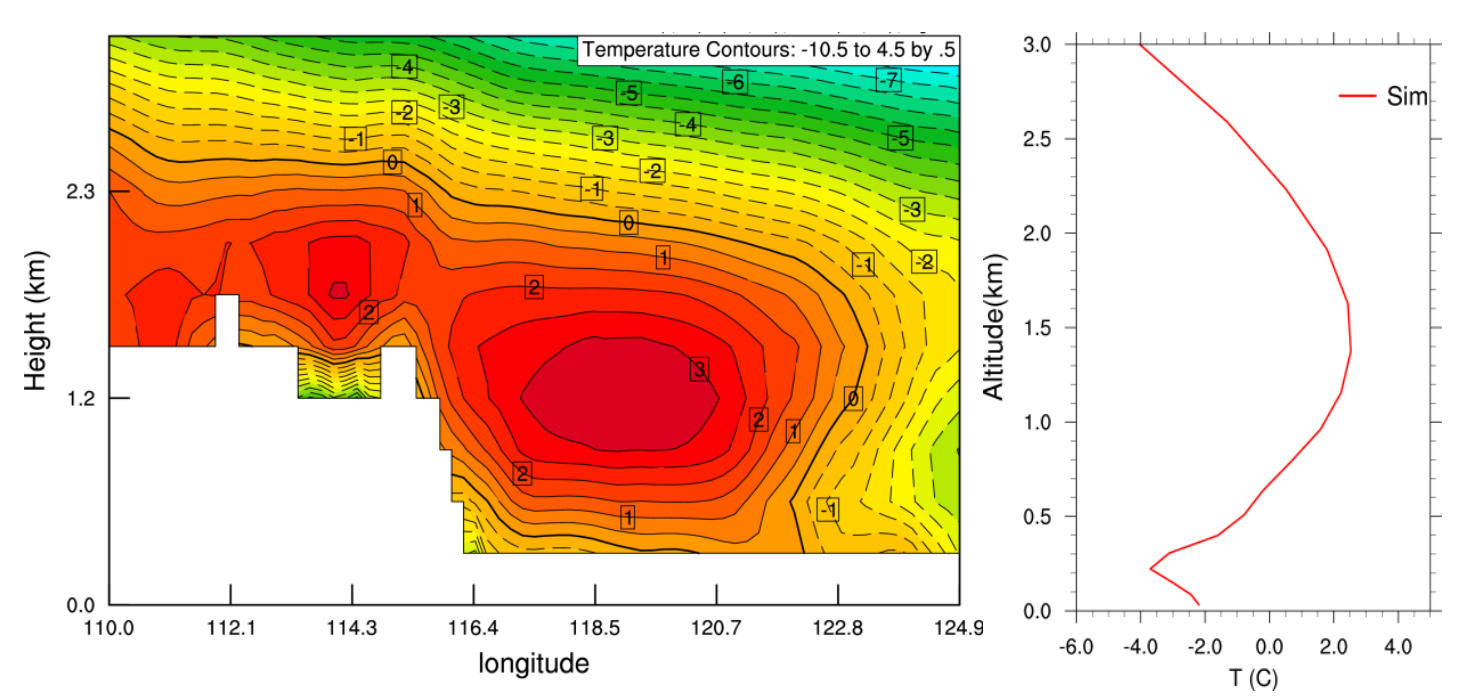

Figure 11: Vertical cross-section of simulated temperature $\left({ }^{\circ} \mathrm{C}\right)$ at $39.91^{\circ} \mathrm{N}$ (left) and vertical profile of temperature (up to $3 \mathrm{~km}$ altitude) in Beijing on 18 January 2010 (right).

Comparison of the model predictions with surface measurements in Shanghai in January 2010 are displayed on Figure 12. The Shanghai region did not experience a particular haze event similar to the one observed in Beijing, but high NOx, $\mathrm{PM}_{2.5}$ and $\mathrm{PM}_{10}$ concentrations of over $80 \mathrm{ppb}, 150 \mu \mathrm{g} \mathrm{m}^{-3}$ and $180 \mathrm{\mu g} \mathrm{m}^{-3}$ respectively were also observed in this region in January 2010. The three WRF-Chem simulations reproduce well the concentrations and temporal variability of $\mathrm{PM}_{2.5}$ and $\mathrm{PM}_{10}$. They exhibit almost similar statistical performances (Table 3$)$ and good agreement with the measurements $(\mathrm{R}>0.73$ and IOA >0.54). We can notice in particular the low MB, MFB and MFE values which meet well the performance goals suggested by Boylan and Russel (2006). The simulations show also good correlation with the observations and reproduce well the temporal variability of $\mathrm{NOx}$ and $\mathrm{O}_{3}$ ( $\mathrm{R}$ higher than 0.5 and 0.62, respectively). They exhibit however significant differences in the predicted $\mathrm{NOx}$ and $\mathrm{O}_{3}$ concentrations. The RAS and HTP simulations tend to overestimate NOx as indicated by the high MB, MFB and MFE values in Table 3, and show low agreement indices (IOA of -0.26 and 0.14, respectively). The MCT simulation shows a better index of agreement with NOx measurements $($ IOA $=$ $0.45)$ but tend to underestimate the NOx concentrations $(\mathrm{MB}=-19.8)$. In general, predicted $\mathrm{NOx}_{\text {and }} \mathrm{O}_{3}$ 
in Shanghai are anti-correlated, and this could explain the systematic lower $\mathrm{O}_{3}$ in RAS and HTP (MFB 779 of -1 and -0.68 respectively) and the better performance of $\mathrm{MCT}(\mathrm{MB}=2.4, \mathrm{MFB}=0.14)$. The 780 differences between the simulations regarding the predicted $\mathrm{NOx}$ and $\mathrm{O}_{3}$ could be driven by the 781 differences in the emissions and their resolution. The high resolution characterizing the HTAPv2 and REASv2 emissions, used in HTP and RAS simulations respectively, better resolves the emission sources, particularly in Shanghai which is close to the ocean, while the MACCity emissions used in MCT are more representative of large areas. Furthermore, as shown on Table 1, NO emissions in Shanghai are higher by more than 30\% in HTAPv2 and REASv2 inventories compared to MACCity.
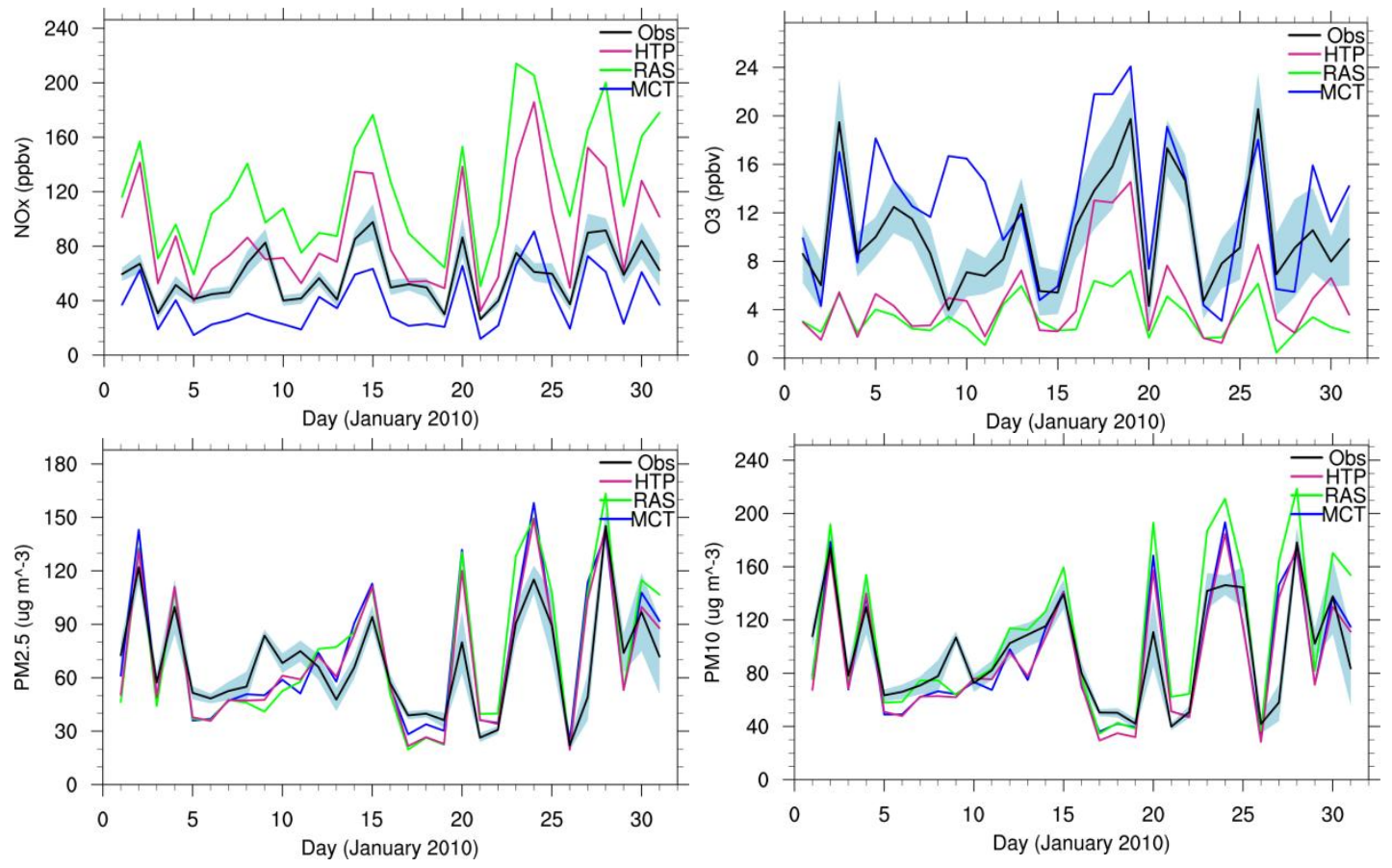

Figure 12: Time series of simulated and observed daily mean NOx, $\mathrm{O}_{3}, \mathrm{PM}_{2.5}$ and $\mathrm{PM}_{10}$ concentrations in Shanghai in January 2010. Standard deviations from the mean observations indicated with shaded area. 

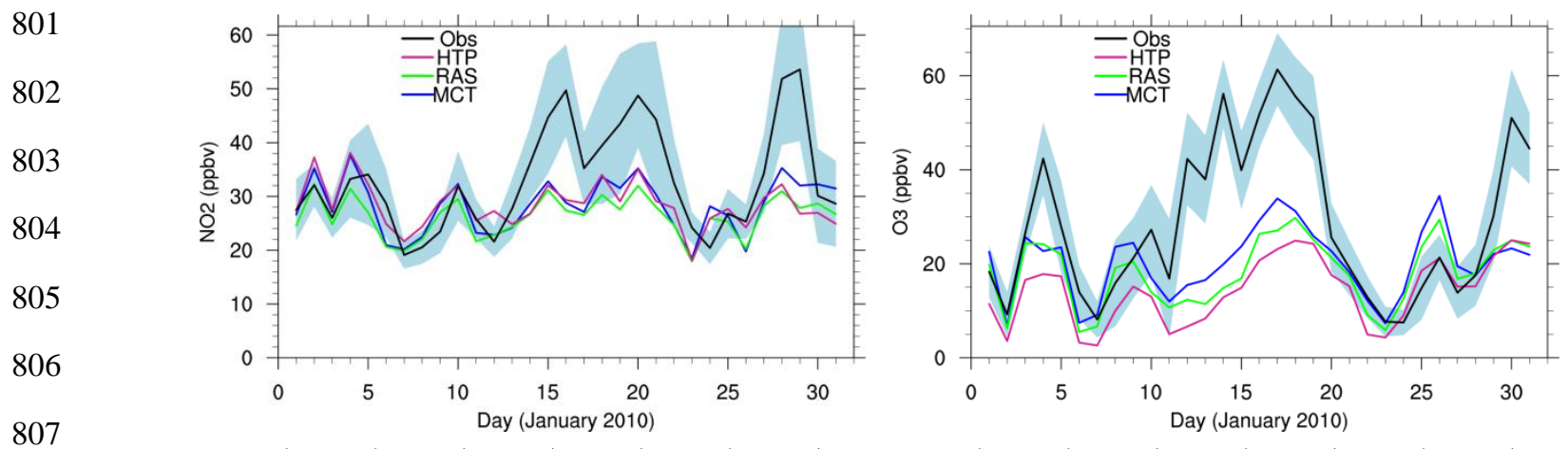

808

809

810

811

812
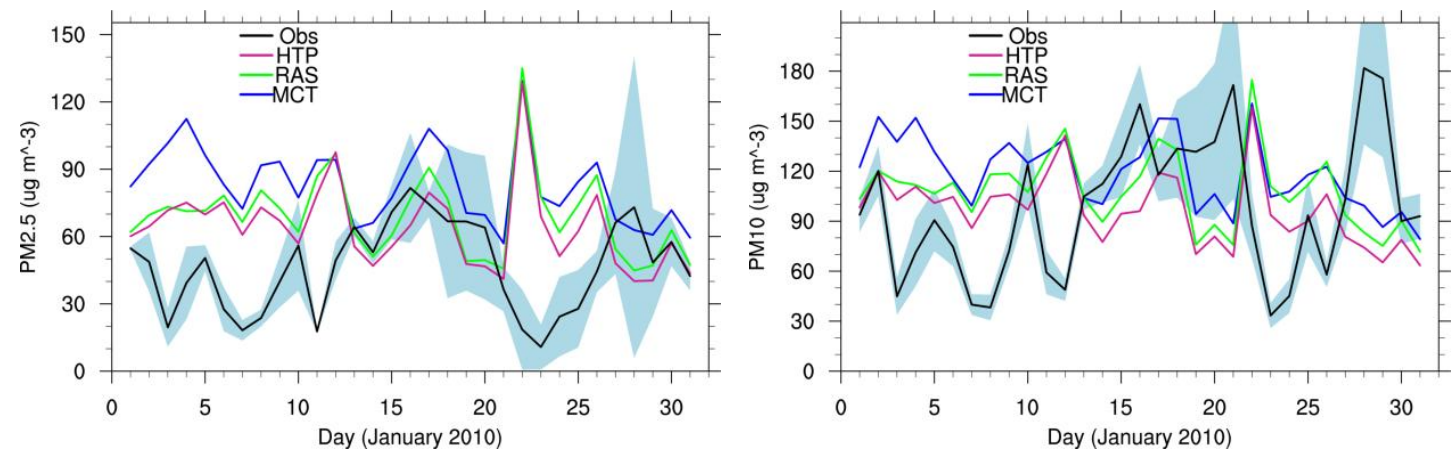

814

815

816

817

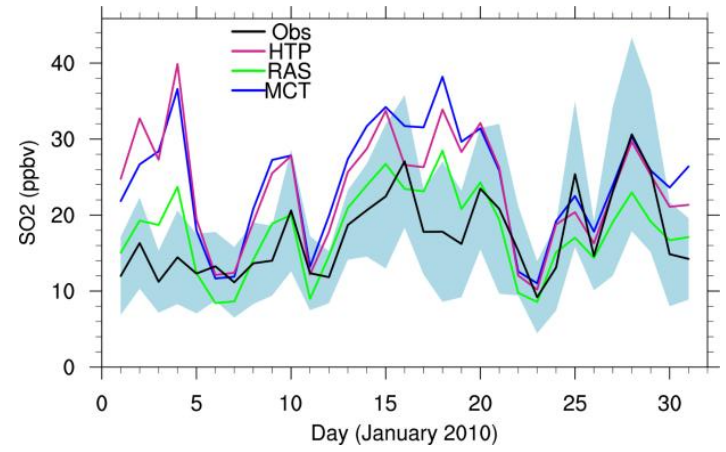

Figure 13: Time series of simulated and observed daily mean $\mathrm{NO}_{2}, \mathrm{O}_{3}, \mathrm{PM}_{2.5}, \mathrm{PM}_{10}$ and $\mathrm{SO}_{2}$ concentrations in Guangzhou for January 2010. Standard deviations from the mean observations indicated with shaded area.

The model results and statistical measures in Guangzhou in January 2010 are illustrated on Figure 13 824 and Table 3, respectively. The simulations produce generally good agreement indices for $\mathrm{NO}_{2}$ and $\mathrm{O}_{3}$ 825 (IOA > 0.45) and comparable statistical measures but tend to underestimate the $\mathrm{O}_{3}$ and $\mathrm{NO}_{2}$ 826 concentrations in mid- and end of January 2010. This is consistent with the statistical indicators on 827 Table 3, which show negative $\mathrm{MB}$ and MFB. There are almost no differences in the predicted $\mathrm{NO}_{2}$ 828 concentrations between the simulations and only slight differences $(\sim 5 \mathrm{ppb})$ are found for $\mathrm{O}_{3}$. This 829 suggests that other processes than emissions are responsible for the underestimation of surface $\mathrm{O}_{3}$ and 
$\mathrm{NO}_{2}$ in the simulations. The meteorological situation in Guangzhou (Figure 4) is characterized by a decrease in wind speed to less than $2 \mathrm{~m} \mathrm{~s}^{-1}$ in mid- and end of January. This leads to unfavourable conditions for the dispersion of pollution and could explain the observed high $\mathrm{NO}_{2}$ concentrations (40$50 \mathrm{ppb}$ ). The temperature increased to around $20^{\circ} \mathrm{C}$ in mid-January, while relative humidity showed the lowest observed values in January 2010. The observed $\mathrm{O}_{3}$ increases could partially be related to the combination of high temperature and low humidity, which can increase the $\mathrm{O}_{3}$ formation rates. While the temperature profile is well predicted by the model, the relative humidity is slightly overestimated and this may have led to a lower $\mathrm{O}_{3}$ production rate in the model. Uncertainties in VOC emissions in the inventories combined with the underestimation of $\mathrm{NO}_{2}$ could also result in less efficient $\mathrm{O}_{3}$ formation in the model. For $\mathrm{SO}_{2}$, the RAS simulation exhibits better agreement with the observations $(\mathrm{IOA}=0.51)$ and higher scores (e.g. $\mathrm{MB}=0.8, \mathrm{MFE}=0.22$ and $\mathrm{R}=0.68$ ) compared to HTP and MCT simulations, which tend to overestimate $\mathrm{SO}_{2}$. The model simulations fail to reproduce correctly the temporal variability of $\mathrm{PM}_{2.5}$ and $\mathrm{PM}_{10}$ in Guangzhou in January 2010. Although the simulations achieve the model performance criteria for particulates (MFE $\leq+0.75 \%$ and $\mathrm{MFB} \leq \pm 0.6)$ proposed by Boylan and Russel (2006), they fail to meet the strict performance goals (MFE $\leq+0.5$ and $\mathrm{MFB} \leq \pm 0.3$ ). As indicated on Figure 4, the precipitation rates in Guangzhou are underestimated in the model in beginning and end of January 2010. This may have led to less removal of aerosols by wet scavenging in the model and could explain the discrepancies between the simulated and observed $\mathrm{PM}_{2.5}$ and $\mathrm{PM}_{10}$. Overall, the results indicate that meteorological conditions have also important impact on the concentrations of pollutants in Guangzhou. Further investigations on e.g. aerosol formation, composition and properties in the Guangzhou region, and on the role of land-sea interaction processes, regional topography and vertical mixing could help better understand the discrepancies between the model and the observations.

\subsection{Evaluation with surface observations in July 2010}

The observed $\mathrm{O}_{3}$ concentrations in Beijing in July 2010 show maximum values of $~ 50$ ppb (Figure 14), which are higher than that in January 2010 ( 25 ppb) due to high photochemical activity in summer. On the other hand, maximum NOx concentrations in July $2010(\sim 35 \mathrm{ppb})$ correspond to the minimum values observed in Beijing in January 2010. Clear differences can be seen between the three model simulations for most of the pollutants. The HTP simulation shows NOx values between 30 and 45 ppb, 
860 which are nearly two times higher than what RAS and MCT have predicted (15-20 ppb). This is in 861 agreement with the differences in NO emissions in Beijing in July, discussed in Sect. 4.1 (see also Table 862 2), which are higher in HTAPv2 than in MACCity and REASv2. The HTP results indicate overestimate 863 of NOx $(\mathrm{MB}=9.3$ and $\mathrm{MFB}=0.23$ on Table 4) while the RAS and MCT simulations show an 864 underestimations with NOx concentrations lower by 10 to $20 \mathrm{ppb}$ compared to the observations (e.g. $865 \mathrm{MB}=-9.9$ and RMSE $=15.4$ for RAS $)$. All the simulations show moderate agreement indices $($ IOA $<$ 866 0.36) and correlation coefficients $(\mathrm{R}<0.39)$ due to the temporal variability of NOx observations, which 867 is not well captured by the simulations. In relation to the underestimation of NOx concentrations, the 868 MCT and RAS results show higher positive $\mathrm{O}_{3}$ biases (e.g. MFB and MFE >0.5) while HTP exhibits 869 better agreement $(\mathrm{IOA}=0.37)$ and correlation with the observations $(\mathrm{R}=0.51)$ and lower bias $(\mathrm{MB}=12.6$ 870 and $\mathrm{MFB}=0.29)$.

Table 4: Statistical skills in Beijing, Shanghai and Guangzhou in July 2010 with the HTP (left columns), RAS (center columns) and MCT (right columns) model simulations.

\begin{tabular}{l|rrr|rrr|rrr|rr|rr|rrr}
\hline Beijing & \multicolumn{3}{|c|}{ NOx } & \multicolumn{3}{|c|}{$\mathbf{O}_{\mathbf{3}}$} & \multicolumn{3}{c|}{$\mathbf{S O}_{\mathbf{2}}$} & \multicolumn{3}{|c|}{$\mathbf{P M}_{\mathbf{2 . 5}}$} & \multicolumn{3}{|c}{$\mathbf{P M}_{\mathbf{1 0}}$} \\
\hline MB & 9.3 & -9.9 & -12.8 & 12.6 & 31.7 & 23.7 & 16.5 & 13.2 & 8.2 & 26.2 & 28.4 & 10.7 & -6.9 & 3.9 & -23.1 \\
MFB & 0.23 & -0.46 & -0.68 & 0.29 & 0.61 & 0.50 & 1.24 & 1.22 & 0.99 & 0.32 & 0.35 & 0.18 & -0.03 & 0.05 & -0.16 \\
MFE & 0.47 & 0.59 & 0.77 & 0.40 & 0.62 & 0.53 & 1.24 & 1.22 & 1.01 & 0.44 & 0.43 & 0.37 & 0.35 & 0.32 & 0.35 \\
RMSE & 23.6 & 15.4 & 18.1 & 21.7 & 36.7 & 29.9 & 20.6 & 14.5 & 9.8 & 46.9 & 43.8 & 35.2 & 55.7 & 51.4 & 55.9 \\
R & 0.39 & 0.25 & 0.04 & 0.51 & 0.37 & 0.31 & 0.23 & 0.44 & 0.39 & 0.48 & 0.61 & 0.58 & 0.46 & 0.56 & 0.50 \\
IOA & 0.14 & 0.36 & 0.23 & 0.37 & -0.14 & 0.07 & -0.65 & -0.56 & -0.32 & 0.41 & 0.44 & 0.55 & 0.47 & 0.51 & 0.48 \\
\hline
\end{tabular}

\begin{tabular}{l|rrr|rrr|rrr|rrr}
\hline \multicolumn{3}{c|}{ Shanghai } & \multicolumn{3}{|c|}{ NOx } & \multicolumn{3}{c|}{$\mathbf{O}_{\mathbf{3}}$} & \multicolumn{3}{|c|}{$\mathbf{P M}_{\mathbf{2 . 5}}$} & \multicolumn{3}{c}{$\mathbf{P M}_{\mathbf{1 0}}$} \\
\hline MB & 29.6 & 61.1 & -3.6 & 2.3 & -1.9 & 16.7 & 35.1 & 44.2 & 33.6 & 43.3 & 66.3 & 41.1 \\
MFB & 0.75 & 1.08 & -0.09 & -0.16 & -0.24 & 0.47 & 0.75 & 0.85 & 0.76 & 0.70 & 0.90 & 0.69 \\
MFE & 0.74 & 1.08 & 0.62 & 0.30 & 0.41 & 0.49 & 0.78 & 0.87 & 0.79 & 0.73 & 0.92 & 0.74 \\
RMSE & 35.4 & 65.6 & 15.7 & 21.6 & 24.3 & 27.6 & 51.7 & 65.2 & 48.6 & 64.3 & 82.4 & 52.1 \\
R & 0.49 & 0.47 & 0.33 & 0.69 & 0.71 & 0.67 & 0.64 & 0.60 & 0.63 & 0.59 & 0.53 & 0.59 \\
IOA & -0.28 & -0.63 & 0.64 & 0.61 & 0.56 & 0.46 & -0.22 & -0.38 & -0.19 & -0.28 & -0.51 & -0.23 \\
\hline
\end{tabular}

\begin{tabular}{l|rrr|rrr|rrr|rrr|rrr}
\hline Guangzhou & \multicolumn{3}{|c|}{$\mathbf{N O}_{\mathbf{2}}$} & \multicolumn{3}{|c|}{$\mathbf{O}_{\mathbf{3}}$} & \multicolumn{3}{c|}{$\mathbf{S O}_{\mathbf{2}}$} & \multicolumn{3}{|c|}{$\mathbf{P M}_{\mathbf{2 . 5}}$} & \multicolumn{3}{|c}{$\mathbf{P M}_{\mathbf{1 0}}$} \\
\hline MB & 3.3 & 0.3 & 0.6 & -25.3 & -21.8 & -22.1 & 12.4 & 4.3 & 6.6 & 4.4 & 2.1 & 8.7 & -0.2 & -2.1 & 4.5 \\
MFB & 0.20 & 0.07 & 0.07 & -0.78 & -0.64 & -0.65 & 0.80 & 0.42 & 0.64 & 0.22 & 0.13 & 0.35 & -0.01 & -0.07 & 0.11 \\
MFE & 0.47 & 0.45 & 0.49 & 0.80 & 0.68 & 0.69 & 1.06 & 0.76 & 0.84 & 0.37 & 0.43 & 0.45 & 0.44 & 0.46 & 0.49 \\
RMSE & 9.9 & 8.4 & 9.1 & 32.2 & 28.8 & 29.1 & 18.9 & 9.80 & 11.6 & 10.2 & 12.1 & 14.7 & 22.9 & 21.7 & 25.5 \\
R & 0.45 & 0.44 & 0.48 & 0.46 & 0.54 & 0.53 & -0.06 & 0.05 & -0.18 & 0.63 & 0.57 & 0.54 & 0.64 & 0.63 & 0.57 \\
IOA & 0.38 & 0.46 & 0.41 & 0.28 & 0.36 & 0.35 & -0.49 & 0.03 & -0.15 & 0.52 & 0.46 & 0.33 & 0.44 & 0.46 & 0.35 \\
\hline
\end{tabular}



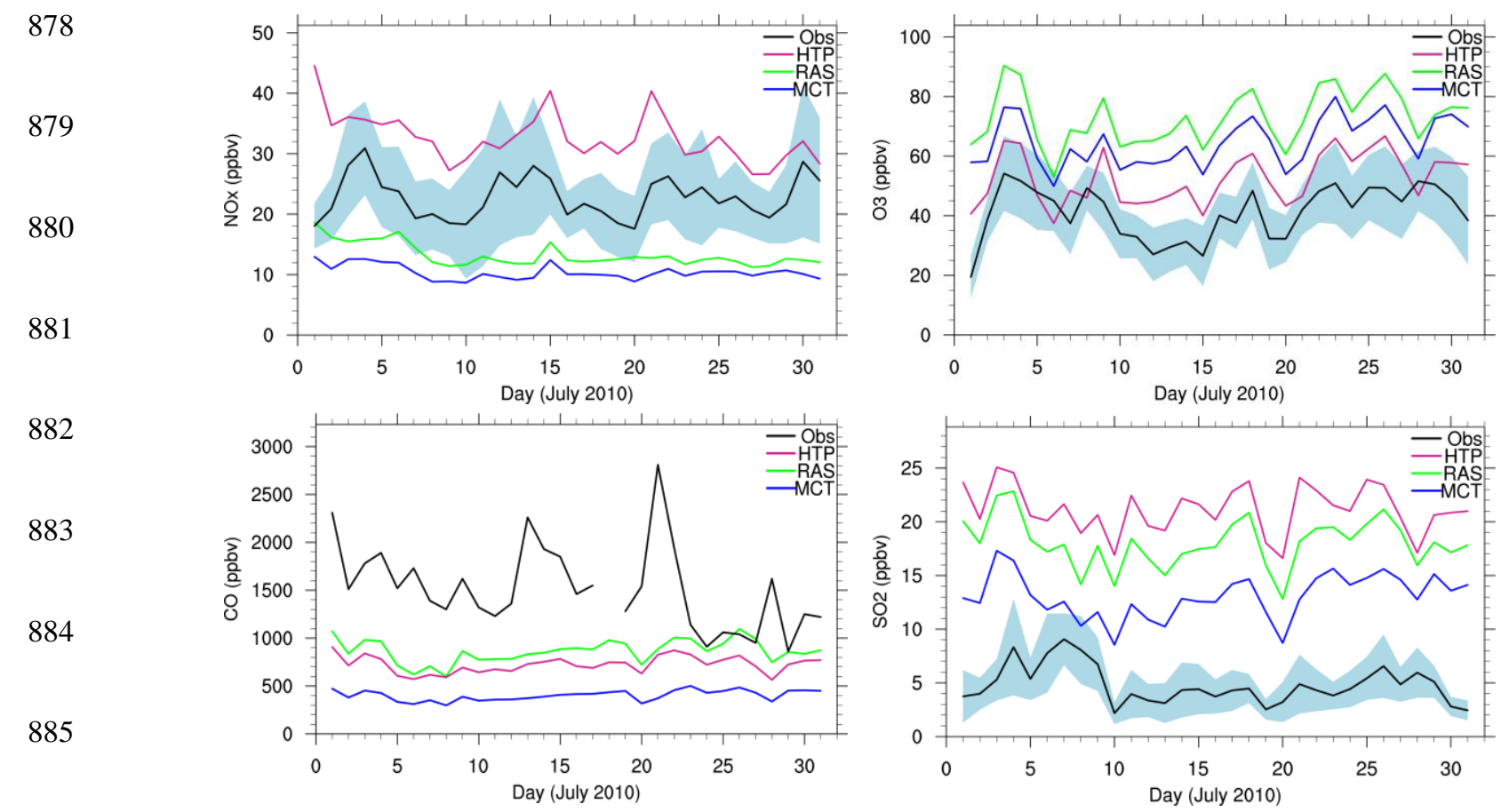

886

887

888

889
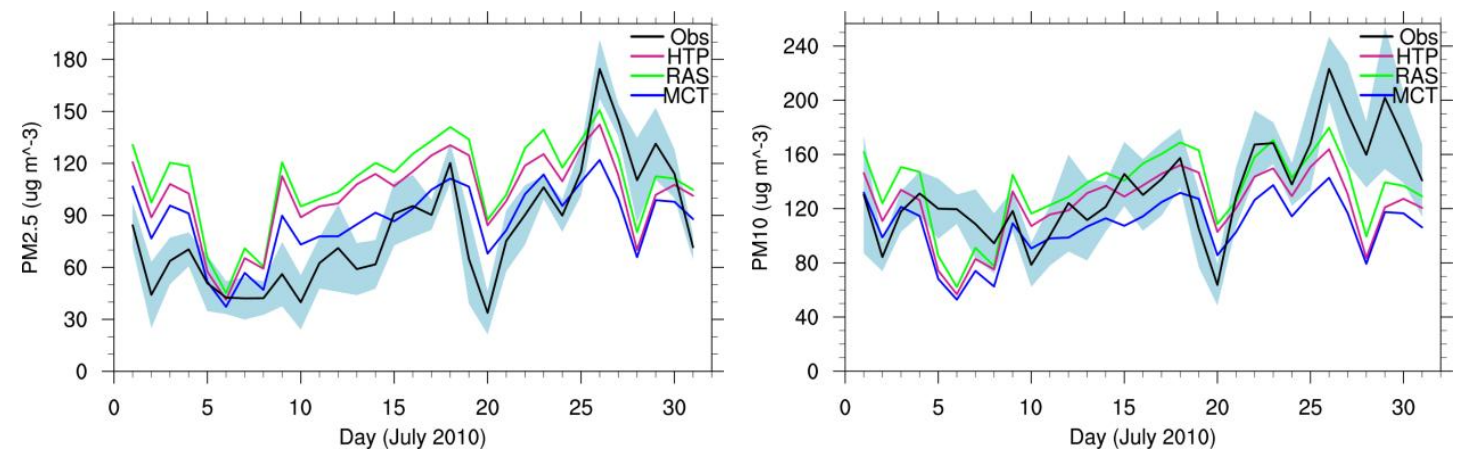

890

Figure 14: Time series of simulated and observed daily mean concentrations of NOx, $\mathrm{O}_{3}, \mathrm{CO}, \mathrm{SO}_{2}, \mathrm{PM}_{2.5}$ and $\mathrm{PM}_{10}$ in Beijing in July 2010. Standard deviations from the 891 mean observations indicated with shaded area.

892

893 As in January, all the simulations underestimate CO concentrations in July 2010 and fail to capture 894 correctly the observed peak concentrations at the CO measurement site in Beijing. The HTP and RAS 895 simulations predicted $\mathrm{CO}$ concentrations $(\sim 1 \mathrm{ppm})$ lower by 0.5 to $1 \mathrm{ppm}$ compared to the observations, 896 while MCT predicted the lowest CO concentrations ( 0.5 ppm) due to lower CO emissions and 897 resolution in the MACCity inventory. For $\mathrm{SO}_{2}$, we can notice the lower concentrations in July (<10 $898 \mathrm{ppb}$ ) compared to observed values in January 2010 (up to $85 \mathrm{ppb}$ ). All the three simulations show 899 overestimation of $\mathrm{SO}_{2}$ by more than of factor of two indicating possible overestimation of $\mathrm{SO}_{2}$ 
900 emissions in summer in the emission inventories. The three simulations reproduce correctly the 901 temporal variability of $\mathrm{PM}_{2.5}$ and $\mathrm{PM}_{10}$ concentrations including the abrupt decreases on $20 \mathrm{July}$ and 902 increases at the end of July. The simulations meet also the performance goal for particulates. Their 903 statistical scores are generally comparable and indicate good agreement (IOA>0.41) with the 904 observations (Table 4).
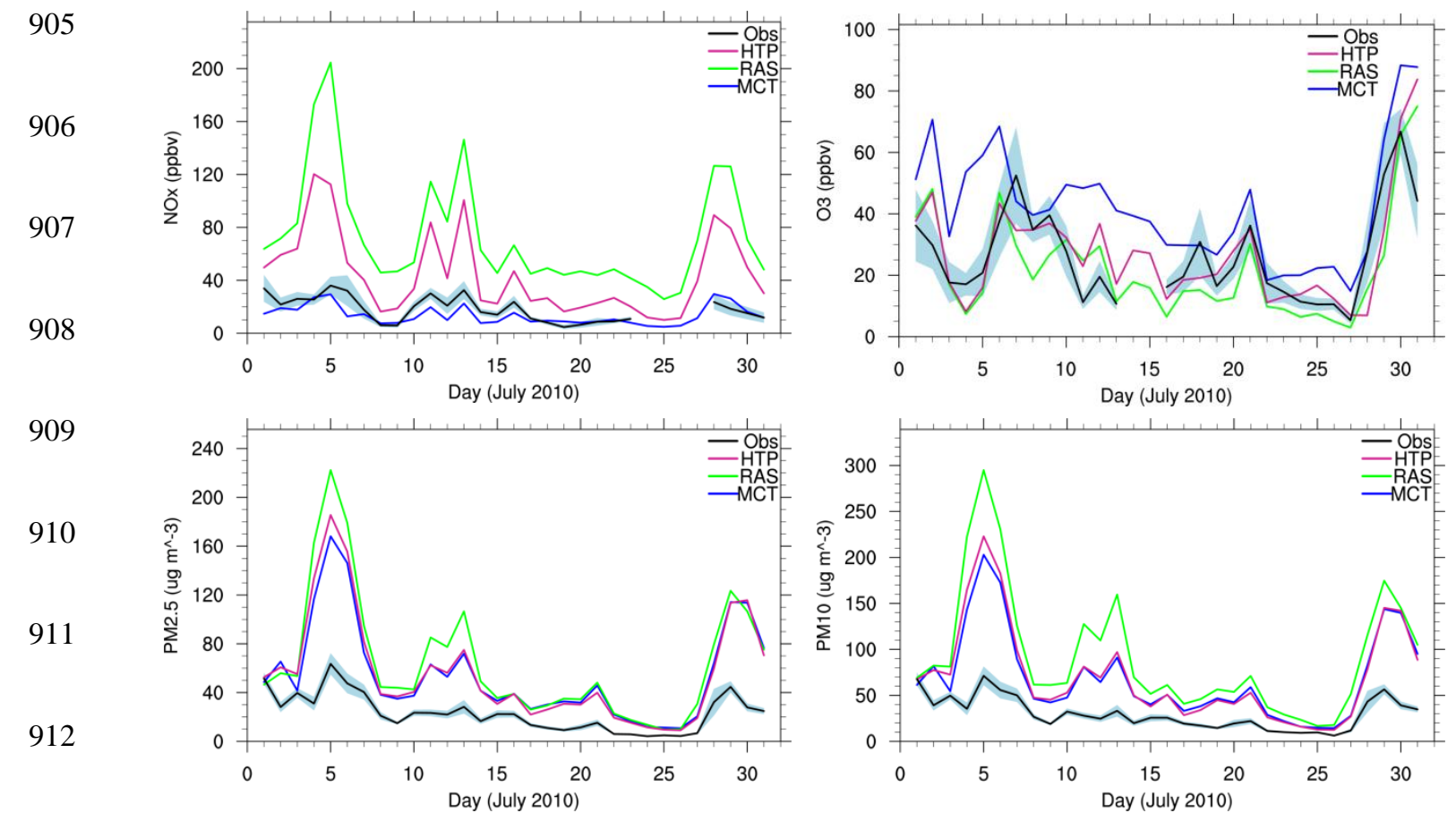

Figure 15: Time series of simulated and observed daily mean $\mathrm{NOx}, \mathrm{O}_{3}, \mathrm{PM}_{2.5}$ and $\mathrm{PM}_{10}$ concentrations in Shanghai in July 2010. Standard deviations from the mean observations indicated with shaded area.

916 The model results for Shanghai in July 2010 (Figure 15) indicate that the MCT simulation captures well 917 the NOx observations, with low bias (MB = -3.6, MFB=-0.09, see Table 4) and good index of 918 agreement $(\mathrm{IOA}=0.64)$. The HTP and RAS simulations overpredict the NOx concentrations (MFB of 9190.75 and 1.08 respectively) and show abrupt and high increases of NOx during the first, second and last 920 weeks of July 2010, which are not seen in the observations. This explains the lower statistical skills and 921 lower agreement of HTP and RAS with the NOx measurements. Despite the good performance of the 922 MCT simulation for NOx, it shows however lower statistical skills for $\mathrm{O}_{3}$ and higher bias $(\mathrm{MFB}=0.47$, 
MFE $=0.49)$ compared to HTP and RAS, which agree better with the observations (e.g. IOA=0.61 and $\mathrm{MB}=2.3$ for $\mathrm{HTP})$.

The results for $\mathrm{PM}_{2.5}$ and $\mathrm{PM}_{10}$ in Shanghai indicate overestimations in all the simulations and abrupt increases which coincide to the time periods of maximum overestimations of NOx in HTP and RAS simulations. The performance goals and criteria for particulates are therefore not achieved (MFB >0.69, MFE >0.74) and the agreement indices are low and negative. The temporal variability is however relatively well captured by the simulations which show relatively good correlation coefficients. Analysis of model prediction of wind speed in Shanghai in July (Sect. 3, see also Figure 3) shows that while wind speed is generally overestimated in the model, rapid decreases with values almost lower than the observations, have occurred during the same time periods of overestimations of $\mathrm{PM}_{2.5}$ and $\mathrm{PM}_{10}$ and NOx concentrations. Such rapid decreases in wind speed and close proximity to emissions sources in particular in HTAPv2 and RASv2 emissions, could have led to strong accumulation of pollution in the model and thus to the overestimations of $\mathrm{PM}_{2.5}$ and $\mathrm{PM}_{10}$ and $\mathrm{NOx}$.

Figure 16 illustrates the model results in Guangzhou in July 2010. The three model simulations show almost similar $\mathrm{O}_{3}$ profiles and capture relatively well the temporal variability of $\mathrm{O}_{3}$ but tend to underestimate the observed concentrations by more than $30 \mathrm{ppb}$, consistent with the statistical scores on Table 4 (negative $\mathrm{MB}$ and $\mathrm{MFB}$ values). The observed $\mathrm{NO}_{2}$ concentrations are well captured by the three simulations, although HTP tends to show an overestimation $(\mathrm{MFB}=0.20)$ and a slightly lower agreement $(\mathrm{IOA}=0.38)$ with the measurements compared to RAS and MCT $(\mathrm{IOA}=0.46$ and 0.41 , respectively). Observed $\mathrm{SO}_{2}$ concentrations in Guangzhou remained below 10 ppb in July 2010 while the simulations showed higher values. In particular, HTP predicted $\mathrm{SO}_{2}$ concentrations higher by more than two times $(\mathrm{MB}=12.4, \mathrm{RMSE}=18.9)$. This was also noticed in Beijing in July and suggests overestimation of $\mathrm{SO}_{2}$ emissions in summer in the three emission inventories. The observed $\mathrm{PM}_{2.5}$ and $\mathrm{PM}_{10}$ concentrations and temporal variability are nicely captured by the HTP and RAS simulations, which meet the strict performance goals for particulates suggested by Boylan and Russel (2006). The MCT simulation shows also good skills (Table 4) and meet the performance criteria for particulates, although it overestimates slightly the $\mathrm{PM}_{2.5}$ concentrations $(\mathrm{MFB}=0.35, \mathrm{MFE}=0.45)$. 

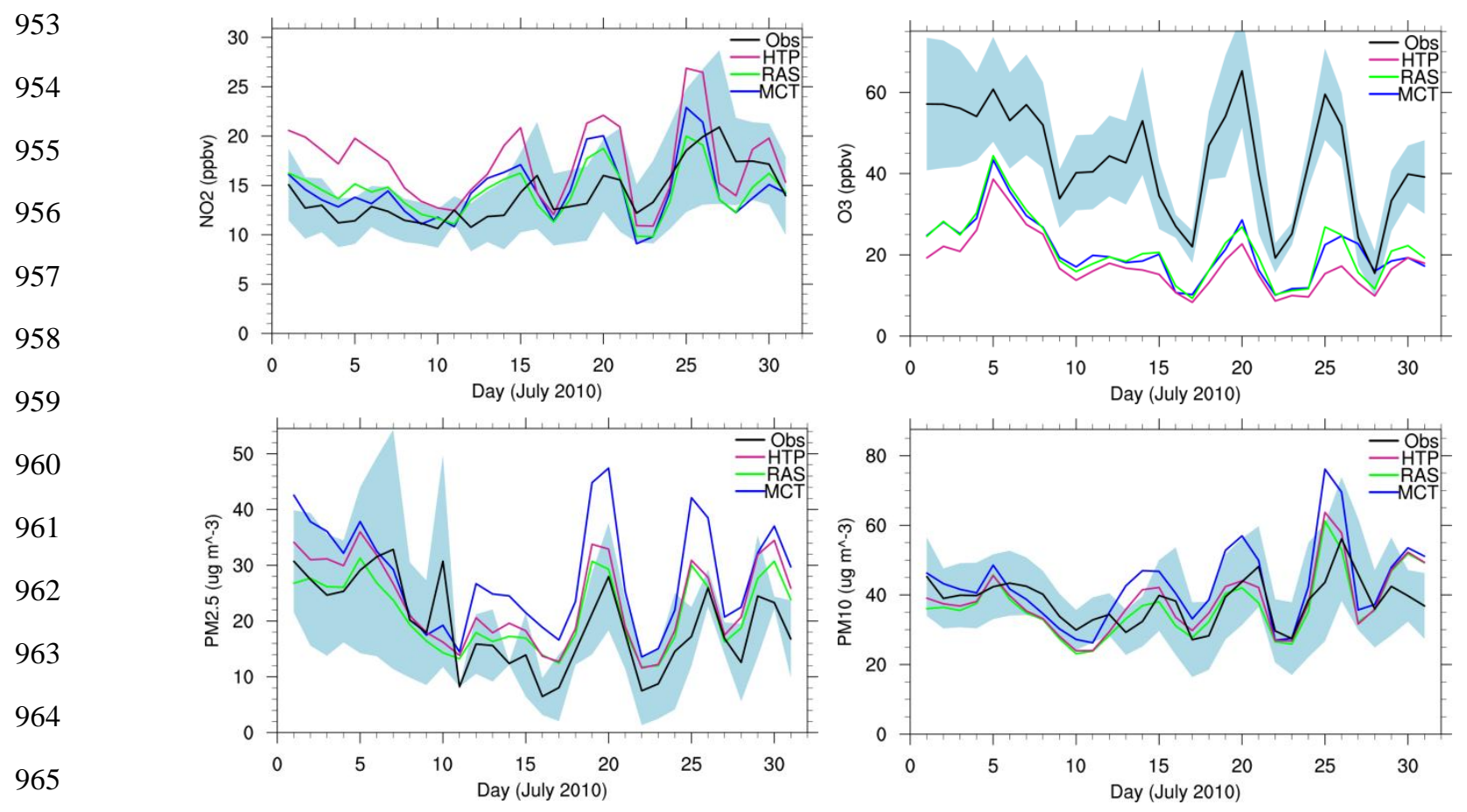

966

967

968

969

970

971

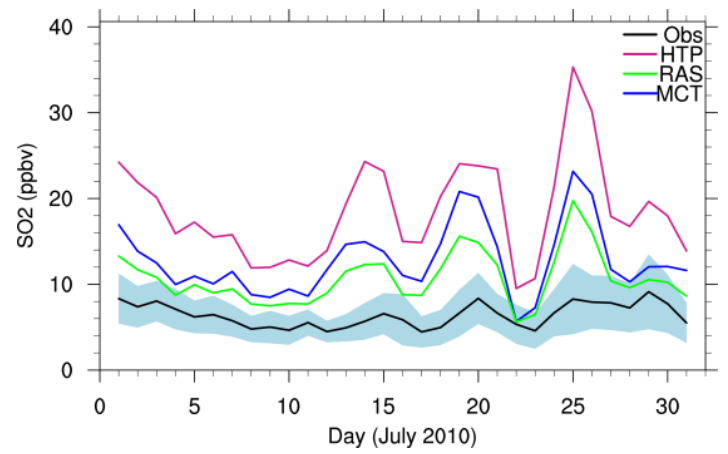

972

Figure 16: Time series of simulated and observed daily mean $\mathrm{NO}_{2}, \mathrm{O}_{3}, \mathrm{PM}_{2.5}$ and $\mathrm{PM}_{10}$ concentrations in Guangzhou for July 2010. Standard deviations from the mean observations indicated with shaded area.

\section{Conclusions}

977 The online coupled model WRF-Chem was used to investigate the air quality characteristics in eastern 978 China and to assess the model performance in January and July 2010. The evaluation of the modelling 979 system was performed using both satellite and ground-based measurements and was conducted 980 specifically for the highly populated and polluted regions of Beijing, Shanghai and Guangzhou. Model 981 simulations were performed using the HTAPv2, REASv2 and MACCity anthropogenic emission 982 inventories to assess the impact of emissions on the model predictions. 
Overall, the selected WRF-Chem configuration shows satisfactory results and captures generally well

984

985

986

987

988

989

990

991

992

993

994

995

996

997

the distributions of major air pollutants in eastern China in both summer and winter conditions. In particular, the defined goals for the concentrations of particulates are met by the model simulations in most of the considered regions. The simulated meteorological fields agree also generally well with the observations in general in the three selected city-clusters, but the model tends to overestimate the maximum values of surface wind speed, as also reported in previous WRF-Chem modelling studies. The ability of the model to capture specific pollution events under specific meteorological conditions is demonstrated with the good performance and statistical skills of the simulations during the pollution event that was observed in Beijing in mid-January 2010. This event led to high concentrations of NOx (150 ppb) CO (6 ppm), $\mathrm{SO}_{2}(80 \mathrm{ppb}) \mathrm{PM}_{2.5}\left(300 \mu \mathrm{g} \mathrm{m}^{-3}\right)$ and $\mathrm{PM}_{10}\left(400 \mu \mathrm{g} \mathrm{m}^{-3}\right)$ and is found to be related to temperature inversion in the lower troposphere, which resulted in a stagnation situation and build-up of air pollution. The HTAPv2-based simulation showed generally better agreement with the observations during this event compared to results of the REASv2-based and MACCity-based simulations.

This study highlights the extent of uncertainties in actual inventories of anthropogenic emissions for China. The HTAPv2, REASv2 and MACCity anthropogenic emissions show differences in magnitude ranging from less than $10 \%$ to more than $80 \%$ for some species (e.g. NO and $\mathrm{CO}$ ) and indicate also differences in the temporal and spatial distribution of the emissions. As a result, large differences in the predicted concentrations of major pollutants are found between the WRF-Chem simulations conducted separately using these emission inventories. For instance, the HTAPv2- and REASv2-based simulations better reproduce the magnitude and spatial distribution of $\mathrm{CO}$ total columns and $\mathrm{NO}_{2}$ tropospheric columns derived from MOPITTv6 and GOME2 satellite observations respectively. On the other hand, the MACCity-based simulation tends to produce lower $\mathrm{CO}$ and $\mathrm{NO}_{2}$ concentrations, and lower performance when compared to satellite observations. The model simulations exhibit also clear differences, in particular in Shanghai and Beijing in January and July 2010 respectively, which can be linked to the differences in the emissions.

This study highlights however that the discrepancies between the model and the observations cannot always be attributed to uncertainties and differences in the emission estimates. Regardless of the emissions applied, the model failed to correctly capture the concentrations and temporal variability of 
air pollutants in some particular cases. For example, inaccuracies in the predicted meteorological

1013

1014

1015

1016

1017

1018

1019

1020

1021

1022

1023

1024

1025

1026

1027

1028

1029

1030

1031

1032

1033

1034

1035

1036

1037

1038

1039

1040

1041

1042

1043

1044

1045

1046

1047 parameters, such as precipitation rates in Guangzhou in January 2010 and wind speed in Shanghai in July 2010, resulted in lower performance and statistical skills in all the simulations. Improved model resolution and better understanding of the processes affecting aerosol formation, composition and properties and atmospheric composition in general in some regions like Guangzhou are therefore required. Correct prediction of the meteorological fields is also key for a reliable air quality prediction particularly during pollution events. Further investigations on the role of land-sea interaction processes, regional topography and vertical mixing could also help better understand the discrepancies between the model and the observations. Overall, this study provided an opportunity to assess the performance of the selected WRF-Chem model settings, and led to the implementation of the model as an operational forecasting system for regional air quality in China.

\section{Acknowledgements}

This work has received research funding from the European Community's Seventh Framework Programme (FP7) under the PANDA project grant agreement $n^{\circ}$ 606719. This work was also partially supported by the National Key Research and Development Program of China (2017YFC0210105), National Natural Science Funds of China (No.41425020).

The authors gratefully acknowledge the computing time granted by the John von Neumann Institute for Computing (NIC) and provided on the supercomputer JURECA at the Jülich Supercomputing Centre (JSC). We acknowledge use of MOZART-4 global model output available at http://www.acom.ucar.edu/wrf-chem/mozart.shtml. We acknowledge also use of the WRF-Chem preprocessor tool $\{$ mozbc, fire_emiss, etc. $\}$ provided by the Atmospheric Chemistry Observations and Modelling Lab (ACOM) of NCAR.

\section{References}

Akimoto, H., Global air quality and pollution, Science, 302(5651):1716-9, 2003.

Amnuaylojaroen, T., Barth, M. C., Emmons, L. K., Carmichael, G. R., Kreasuwun, J., Prasitwattanaseree, S., and Chantara, S.: Effect of different emission inventories on modeled ozone and carbon monoxide in Southeast Asia, Atmos. Chem. Phys., 14, 12983-13012, doi:10.5194/acp-14-129832014, 2014.

Ashmore, M. R.: Assessing the future global impacts of ozone on vegetation. Plant, Cell \& Environment, 28: 949-964. doi:10.1111/j.1365-3040.2005.01341.x, 2005. 
Boersma, K. F., and Eskes, H., Assimilated SCIAMACHY NO2 fields, HDF data file user manual, (http://www.temis.nl/airpollution/no2col/papers/no2col_hdf_docu.pdf, last accessed 15.02.2018), 2004.

Boersma, K. F., Eskes, H. J., and Brinksma, E. J.: Error analysis for tropospheric $\mathrm{NO}_{2}$ retrieval from space, J. Geophys. Res., 109, D04311, doi:10.1029/2003JD003962, 2004.

Boersma, K. F., Eskes, H. J., Veefkind, J. P., Brinksma, E. J., van der A, R. J., Sneep, M., van den Oord, G. H. J., Levelt, P. F., Stammes, P., Gleason, J. F., and Bucsela, E. J.: Near-real time retrieval of tropospheric $\mathrm{NO}_{2}$ from OMI, Atmos. Chem. Phys., 7, 2103-2118, doi:10.5194/acp-7-2103-2007, 2007.

Bouarar, I., X. Wang and Brasseur, G. P. (Eds.), Air Pollution in Asia: An Integrated Perspective, Springer, ISBN 978-3-319-59489-7, 2017.

Boylan, J. W., and A. G. Russell, PM and light extinction model performance metrics, goals, and criteria for three-dimensional air quality models. Atm. Env., 40:4946-4959, 2006.

Boynard, A., Clerbaux, C., Clarisse, L., Safieddine, S., Pommier, M., Van Damme, M., Bauduin, S., Oudot, C., Hadji-Lazaro, J., Hurtmans, D., Coheur, P.-F, First simultaneous space measurements of atmospheric pollutants in the boundary layer from IASI: A case study in the North China Plain, Geophys. Res. Lett., 41, 645-651, doi:10.1002/2013GL058333, 2014.

Brasseur, G. P. and D. J. Jacob, Modeling of Atmospheric Chemistry, Cambridge University Press, 2017.

Brasseur, G. P., J. Orlando, and G. Tyndall, Atmospheric Chemistry and Global Change, Oxford University Press, New York, 1999.

Callies, J., Corpaccioli, E., Eisinger, M., Hahne, A., and Lefebvre, A.: GOME-2 - Metop's Second Generation Sensor for Operational Ozone Monitoring, ESA Bull.-Eur. Space, 102, 28-36, 2000.

Chatani, S. and Sudo, K.: Influences of the variation in inflow to East Asia on surface ozone over Japan during 1996-2005, Atmos. Chem. Phys., 11, 8745-8758, doi:10.5194/acp-11-8745-2011, 2011.

Chen, F., and J. Dudhia, Coupling an advanced land surface-hydrology model with the Penn StateNCAR MM5 modeling system. Part I: Model implementation and sensitivity. Mon. Wea. Rev., 129, 569-585, 2001.

Chin, M., P. Ginoux, S. Kinne, B. N. Holben, B. N. Duncan, R. V. Martin, J. A. Logan, A. Higurashi, and T. Nakajima, Tropospheric aerosol optical thickness fromt he GOCART model and comparisons with satellite and sunphotometer measurements, J. Atmos. Sci. 59, 461-483, 2002.

Chou, M., M.J. Suarez, C. Ho, M.M. Yan, and K. Lee, Parameterizations for Cloud Overlapping and Shortwave Single-Scattering Properties for Use in General Circulation and Cloud Ensemble Models. J. Climate, 11, 202-214, 1998. 
Deeter, M. N., S. Martínez-Alonso, D. P. Edwards, L. K. Emmons, J. C. Gille, H. M. Worden, C. Sweeney, J. V. Pittman, B. C. Daube, and S. C. Wofsy, The MOPITT Version 6 product: algorithm enhancements and validation, Atmos. Meas. Tech., 7(11), 3623-3632, doi:10.5194/amt-7-3623-2014, 2014.

Emmons, L. K., Walters, S., Hess, P. G., Lamarque, J.-F., Pfister, G. G., Fillmore, D., Granier, C., Guenther, A., Kinnison, D., Laepple, T., Orlando, J., Tie, X., Tyndall, G., Wiedinmyer, C., Baughcum, S. L., and Kloster, S.: Description and evaluation of the Model for Ozone and Related chemical Tracers, version 4 (MOZART-4), Geosci. Model Dev., 3, 43-67, doi:10.5194/gmd-3-43-2010, 2010.

Eskes, H. J. and Boersma, K. F.: Averaging kernels for DOAS total-column satellite retrievals, Atmos. Chem. Phys., 3, 1285-1291, doi:10.5194/acp-3-1285-2003, 2003.

Eskes, H., Huijnen, V., Arola, A., Benedictow, A., Blechschmidt, A.-M., Botek, E., Boucher, O., Bouarar, I., Chabrillat, S., Cuevas, E., Engelen, R., Flentje, H., Gaudel, A., Griesfeller, J., Jones, L., Kapsomenakis, J., Katragkou, E., Kinne, S., Langerock, B., Razinger, M., Richter, A., Schultz, M., Schulz, M., Sudarchikova, N., Thouret, V., Vrekoussis, M., Wagner, A., and Zerefos, C.: Validation of reactive gases and aerosols in the MACC global analysis and forecast system, Geosci. Model Dev., 8, 3523-3543, https://doi.org/10.5194/gmd-8-3523-2015, 2015.

Fan, Q., Lan, J., Liu, Y., Wang, X., Chan, P., Hong, Y., Feng, Y., Liu, Y., Zeng, Y., Liang, G., Process analysis of regional aerosol pollution during spring in the Pearl River Delta region, China, Atmos. Env., 122, 829-838, 2015.

Fast, J. D., Gustafson Jr., W. I., Easter, R. C., Zaveri, R. A., Barnard, J. C., Chapman, E. G., Grell, G. A., and Peckham, S. E.: Evolution of ozone, particulates, and aerosol direct radiative forcing on the vicinity of Houston using a fully coupled meteorology-chemistry-aerosol model, J. Geophys. Res., 111,D21305, doi:10.1029/2005JD006721, 2006.

Flemming, J., Inness, A., Flentje, H., Huijnen, V., Moinat, P., Schultz, M. G., and Stein, O.: Coupling global chemistry transport models to ECMWF's integrated forecast system, Geosci. Model Dev., 2, 253-265, doi:10.5194/gmd-2-253-2009, 2009.

Flemming, J., Huijnen, V., Arteta, J., Bechtold, P., Beljaars, A., Blechschmidt, A.-M., Diamantakis, M., Engelen, R. J., Gaudel, A., Inness, A., Jones, L., Josse, B., Katragkou, E., Marecal, V., Peuch, V.-H., Richter, A., Schultz, M. G., Stein, O., and Tsikerdekis, A.: Tropospheric chemistry in the Integrated Forecasting System of ECMWF, Geosci. Model Dev., 8, 975-1003, https://doi.org/10.5194/gmd-8-975$2015,2015$.

Flemming, J., Benedetti, A., Inness, A., Engelen, R. J., Jones, L., Huijnen, V., Remy, S., Parrington, M., Suttie, M., Bozzo, A., Peuch, V.-H., Akritidis, D., and Katragkou, E.: The CAMS interim Reanalysis of Carbon Monoxide, Ozone and Aerosol for 2003-2015, Atmos. Chem. Phys., 17, 1945-1983, doi:10.5194/acp-17-1945-2017, 2017. 
1136 Freitas, S. R., Longo, K. M., Chatfield, R., Latham, D., Silva Dias, M. A. F., Andreae, M. O., Prins, E., 1137 Santos, J. C., Gielow, R., and Carvalho Jr., J. A.: Including the sub-grid scale plume rise of vegetation 1138 fires in low resolution atmospheric transport models, Atmos. Chem. Phys., 7, 3385-3398, doi:10.5194/acp-7-3385-2007, 2007.

Fu, J. S., Hsu, N. C., Gao, Y., Huang, K., Li, C., Lin, N.-H., and Tsay, S.-C.: Evaluating the influences of biomass burning during 2006 BASE-ASIA: a regional chemical transport modeling, Atmos. Chem. Phys., 12, 3837-3855, https://doi.org/10.5194/acp-12-3837-2012, 2012.

Geng, H., Hwang, H., Liu, X., Dong, S., and Ro, C.-U.: Investigation of aged aerosols in size-resolved Asian dust storm particles transported from Beijing, China, to Incheon, Korea, using low- $Z$ particle EPMA, Atmos. Chem. Phys., 14, 3307-3323, doi:10.5194/acp-14-3307-2014, 2014.

Ginoux, P., Chin, M., Tegen, I., Prospero, J. M., Holben, B., Dubovik, O., and Lin, S. J.: Sources and distributions of dust taerosols simulated with the GOCART model, J. Geophys. Res. Atmos., 106, 20255-20273, 2001.

Granier, C., B. Bessagnet, T. Bond, A. D’Angiola, H. Denier van der Gon, G.J. Frost, A. Heil, M. Kainuma, J. Kaiser, S. Kinne, Z. Klimont, S. Kloster, J.-F. Lamarque, C. Liousse, T. Matsui, F. Meleux, A. Mieville, T. Ohara, K. Raihi, M. Schultz, S. J. Smith, A. M. Thomson, J. van Aardenne, and G. van der Werf, 2011, Evolution of anthropogenic and biomass burning emissions of air pollutants at global and regional scales during the 1980-2010 period, Climatic Change, 109:163- 190. DOI: 10.1007/s10584-011-0154-1, 2011.

Granier, C., Doumbia, T., Granier, L., Sindelarova, K., Frost, G. J., Bouarar, I., Liousse, C., Darras, S. and J. Stavrakou, Antrhopogenic Emissions in Asia. In: Bouarar I., Wang X. and Brasseur G.-P. (Eds.) Air Pollution in Asia: An Integrated Perspective. Springer, ISBN 978-3-319-59489-7, 2017.

Grell, G.A., S.E. Peckham, R. Schmitz, S.A. McKeen, G. Frost, W.C. Skamarock, B. Eder, Fully coupled online chemistry within the WRF model, Atmos. Environ., 39, pp. 6957-6975, 2005.

Grell, G. A. and Freitas, S. R.: A scale and aerosol aware stochastic convective parameterization for weather and air quality modeling, Atmos. Chem. Phys., 14, 5233-5250, doi:10.5194/acp-14-5233-2014, 2014.

Guenther, A., Karl, T., Harley, P., Wiedinmyer, C., Palmer, P. I., and Geron, C.: Estimates of global terrestrial isoprene emissions using MEGAN (Model of Emissions of Gases and Aerosols from Nature), Atmos. Chem. Phys., 6, 3181-3210, doi:10.5194/acp-6-3181-2006, 2006.

Guo, S., Hu, M., Zamora, M. L., Peng, J., Shang, D., Zheng, J., Du, Z., Wu, Z., Shao, M., Zeng, L., Molina, M. J. and R. Zhang, Elucidating severe urban haze formation in China, Proc. Natl. Acad. Sci. USA, 111(49): 17373-17378., 2014. 
Hamra, G. B., Laden, F., Cohen, A. J., Raaschou-Nielsen, O., Brauer, M., and D. Loomis, Lung Cancer and Exposure to Nitrogen Dioxide and Traffic: A Systematic Review and Meta-Analysis, Environ Health Perspect, 123 | 11, DOI:10.1289/ehp.1408882, 2015.

Hong, S. Y., Y. Noh, and J. Dudhia, A new vertical diffusion package with an explicit treatment of entrainment processes, Mon. Weather Rev., 134(9), 2318-2341, doi:10.1175/Mwr3199.1, 2006.

Huang, K., Zhuang, G., Wang, Q., Fu, J. S., Lin, Y., Liu, T., Han, L., and Deng, C.: Extreme haze pollution in Beijing during January 2013: chemical characteristics, formation mechanism and role of fog processing, Atmos. Chem. Phys. Discuss., 14, 7517-7556, doi:10.5194/acpd-14-7517-2014, 2014.

Huang, R.-J., Y. Zhang, et al., High secondary aerosol contribution to particulate pollution during haze events in China. Nature 514(7521): 218-222, 2014.

Inness, A., Baier, F., Benedetti, A., Bouarar, I., Chabrillat, S., Clark, H., Clerbaux, C., Coheur, P., Engelen, R. J., Errera, Q., Flemming, J., George, M., Granier, C., Hadji-Lazaro, J., Huijnen, V., Hurtmans, D., Jones, L., Kaiser, J. W., Kapsomenakis, J., Lefever, K., Leitão, J., Razinger, M., Richter, A., Schultz, M. G., Simmons, A. J., Suttie, M., Stein, O., Thépaut, J.-N., Thouret, V., Vrekoussis, M., Zerefos, C., and the MACC team: The MACC reanalysis: an $8 \mathrm{yr}$ data set of atmospheric composition, Atmos. Chem. Phys., 13, 4073-4109, doi:10.5194/acp-13-4073-2013, 2013.

Jacob, D. J., J. A. Logan, and P. P. Murti, Effect of rising Asian emissions on surface ozone in the United States, Geophys. Res. Lett., 26, 2175-2178, 1999.

Janssens-Maenhout, G., Crippa, M., Guizzardi, D., Dentener, F., Muntean, M., Pouliot, G., Keating, T., Zhang, Q., Kurokawa, J., Wankmüller, R., Denier van der Gon, H., Kuenen, J. J. P., Klimont, Z., Frost, G., Darras, S., Koffi, B., and Li, M.: HTAP_v2.2: a mosaic of regional and global emission grid maps for 2008 and 2010 to study hemispheric transport of air pollution, Atmos. Chem. Phys., 15, 1141111432, doi:10.5194/acp-15-11411-2015, 2015.

Jiménez, P. A., and J. Dudhia, Improving the Representation of Resolved and Unresolved Topographic Effects on Surface Wind in the WRF Model. J. Appl. Meteor. Climatol., 51, 300-316, doi: 10.1175/JAMC-D-11-084.1, 2012.

Kurokawa, J., Ohara, T., Uno, I., Hayasaki, M., and Tanimoto, H.: Influence of meteorological variability on interannual variations of springtime boundary layer ozone over Japan during 1981-2005, Atmos. Chem. Phys., 9, 6287-6304, doi:10.5194/acp-9-6287-2009, 2009.

Kurokawa, J., Ohara, T., Morikawa, T., Hanayama, S., Janssens-Maenhout, G., Fukui, T., Kawashima, K., and Akimoto, H.: Emissions of air pollutants and greenhouse gases over Asian regions during 20002008: Regional Emission inventory in ASia (REAS) version 2, Atmos. Chem. Phys., 13, 11019-11058, doi:10.5194/acp-13-11019-2013, 2013.

Kampa, M., and Castanas, E., Human health effects of air pollution, Environmental Pollution, 151:362367, DOI: 10.1016/j.envpol.2007.06.012, 2008. 
Kang et al., New Categorical Metrics for Air Quality Model Evaluation, J. Appl. Meteorol. Climatol., 2006.

Leisner, C. P. and Ainsworth, E. A.: Quantifying the effects of ozone on plant reproductive growth and

development, Global Change Biol., 18, 606-616, 2012.

Liang, Q., Jaeglé, L., Jaffe, D. A., Weiss-Penzias, P., Heckman, A., and Snow, J. A.: Long-range transport of Asian pollution to the northeast Pacific: Seasonal variations and transport pathways of carbon monoxide, J. Geophys. Res., 109, D23S07, doi:10.1029/2003JD004402, 2004.

Liao, J., Wang, T., Wang, X., Xie, M., Jiang, Z., Huang, X., Zhu, J., Impacts of different urban canopy schemes in WRF/Chem on regional climate and air quality in Yangtze_River_Delta, China, J. Atmos. Res., 145-146:226-243, DOI: 10.1016/j.atmosres.2014.04.005, 2014.

Lin, M., Fiore, A. M., Horowitz, L.W., Cooper, O. R., Naik, V., Holloway, J., Johnson, B. J., Middlebrook, A. M., Oltmans, S. J., Pollack, I. B., Ryerson, T. B., Warner, J. X. and Wiedinmyer, C., and Wilson, J., Wyman, B., Transport of Asian ozone pollution into surface air over the western United States in spring, J. Geophys. Res., 117(D21), 2156-2202, doi:10.1029/2011JD016961, 2012.

Ma, J., Richter, A., Burrows, J.P., Nüß, H., VanAardenne, J.A., Comparison of model-simulated tropospheric $\mathrm{NO}_{2}$ over China with GOME-satellite data. Atmospheric Environment, 40 . pp. 593-604, 2006.

Marécal, V., Peuch, V.-H., Andersson, C., Andersson, S., Arteta, J., Beekmann, M., Benedictow, A., Bergström, R., Bessagnet, B., Cansado, A., Chéroux, F., Colette, A., Coman, A., Curier, R. L., Denier van der Gon, H. A. C., Drouin, A., Elbern, H., Emili, E., Engelen, R. J., Eskes, H. J., Foret, G., Friese, E., Gauss, M., Giannaros, C., Guth, J., Joly, M., Jaumouillé, E., Josse, B., Kadygrov, N., Kaiser, J. W., Krajsek, K., Kuenen, J., Kumar, U., Liora, N., Lopez, E., Malherbe, L., Martinez, I., Melas, D., Meleux, F., Menut, L., Moinat, P., Morales, T., Parmentier, J., Piacentini, A., Plu, M., Poupkou, A., Queguiner, S., Robertson, L., Rouïl, L., Schaap, M., Segers, A., Sofiev, M., Tarasson, L., Thomas, M., Timmermans, R., Valdebenito, Á., van Velthoven, P., van Versendaal, R., Vira, J., and Ung, A.: A regional air quality forecasting system over Europe: the MACC-II daily ensemble production, Geosci. Model Dev., 8, 2777-2813, https://doi.org/10.5194/gmd-8-2777-2015, 2015.

Martin, R. V., Chance, K., Jacob, D. J., et al.: An Improved Retrieval of Tropospheric Nitrogen Dioxide from GOME, J. Geophys. Res., 107 (D20), 4437-4457, doi:10.1029/2001JD001027, 2002.

Mlawer, E. J., S. J. Taubman, P. D. Brown, M. J. Iacono, and S. A. Clough, Radiative transfer for inhomogeneous atmosphere: RRTM, a validated correlated-k model for the longwave. J. Geophys. Res., 102(D14), 16 663-16 682, 1997.

Osada, K., Ohara, T., Uno, I., Kido, M., and Iida, H.: Impact of Chinese anthropogenic emissions on submicrometer aerosol concentration at Mt. Tateyama, Japan, Atmos. Chem. Phys., 9, 9111-9120, doi:10.5194/acp-9-9111-2009, 2009. 
Quennehen, B., Raut, J.-C., Law, K. S., Daskalakis, N., Ancellet, G., Clerbaux, C., Kim, S.-W., Lund,

M. T., Myhre, G., Olivié, D. J. L., Safieddine, S., Skeie, R. B., Thomas, J. L., Tsyro, S., Bazureau, A., Bellouin, N., Hu, M., Kanakidou, M., Klimont, Z., Kupiainen, K., Myriokefalitakis, S., Quaas, J., Rumbold, S. T., Schulz, M., Cherian, R., Shimizu, A., Wang, J., Yoon, S.-C., and Zhu, T.: Multi-model evaluation of short-lived pollutant distributions over east Asia during summer 2008, Atmos. Chem. Phys., 16, 10765-10792, doi:10.5194/acp-16-10765-2016, 2016.

Richter, A., and J. P. Burrows, Tropospheric $\mathrm{NO}_{2}$ from GOME measurements, Adv. Space Res., 29, 1673-1683, 2002.

Sinha, B., Singh Sangwan, K., Maurya, Y., Kumar, V., Sarkar, C., Chandra, B. P., and Sinha, V.: Assessment of crop yield losses in Punjab and Haryana using 2 years of continuous in situ ozone measurements, Atmos. Chem. Phys., 15, 9555-9576, doi:10.5194/acp-15-9555-2015, 2015.

Sitch, S., Cox, P.M., Collins, W.J., Huntingford, C., Indirect radiative forcing of climate change through ozone effects on the land-carbon sink. Nature. 448: 791-794, 2007.

Skamarock, W. C., and Coauthors, A description of the Advanced Research WRF version 3. NCAR Tech. Note NCAR/TN-4751 STR, 125 pp. [http://www2.mmm.ucar.edu/wrf/users/docs/arw_v3.pdf], 2008.

Stein, O., Schultz, M. G., Bouarar, I., Clark, H., Huijnen, V., Gaudel, A., George, M., and Clerbaux, C.: On the wintertime low bias of Northern Hemisphere carbon monoxide found in global model simulations, Atmos. Chem. Phys., 14, 9295-9316, https://doi.org/10.5194/acp-14-9295-2014, 2014.

Stohl, A., Forster, C., Huntrieser, H., Mannstein, H., McMillan, W. W., Petzold, A., Schlager, H., and Weinzierl, B.: Aircraft measurements over Europe of an air pollution plume from Southeast Asia aerosol and chemical characterization, Atmos. Chem. Phys., 7, 913-937, doi:10.5194/acp-7-913-2007, 2007.

Thompson, G., Rasmussen, R. M., and K. Manning, Explicit forecasts of winter precipitation using an improved bulk microphysics scheme. Part I: Description and sensitivity analysis. Mon. Wea. Rev., 132, 519-542, 2004.

Thompson, G., Field, P. R., Rasmussen, R. M., and W. D. Hall, Explicit forecasts of winter precipitation using an improved bulk microphysics scheme. Part II: Implementation of a new snow parameterization. Mon. Wea. Rev., 136, 5095-5115, 2008.

Tuccella, P., Curci, G., Visconti, G., Bessagnet, B., Menut, L., and Park, R. J.: Modeling of gas and aerosol with WRF/Chem over Europe: Evaluation and sensitivity study, J. Geophys. Res.-Atmos., 117, D03303, doi:10.1029/2011jd016302, 2012.

UNECE, 2010. Hemispheric Transport of Air Pollution 2010: Part A, Ozone and Particulate Matter. Air Pollution Studies N0 17. Dentener, F., Keating, T., and Akimoto, H. (Eds.), United Nations Publication, New York and Geneva (2010) ECE/EB.AIR/100. 
Wagner, A., Blechschmidt, A.-M., Bouarar, I., Brunke, E.-G., Clerbaux, C., Cupeiro, M., Cristofanelli, P., Eskes, H., Flemming, J., Flentje, H., George, M., Gilge, S., Hilboll, A., Inness, A., Kapsomenakis, J., Richter, A., Ries, L., Spangl, W., Stein, O., Weller, R., and Zerefos, C.: Evaluation of the MACC operational forecast system - potential and challenges of global near-real-time modelling with respect to reactive gases in the troposphere, Atmos. Chem. Phys., 15, 14005-14030, doi:10.5194/acp-15-14005$2015,2015$.

Wang, X., and Coauthors, WRF-Chem simulation of East Asian air quality: Sensitivity to temporal and vertical emissions distributions. Atmos. Environ., 44, 660-669, doi:10.1016/J. Atmos. Env. 2009.11.011, 2010 .

Wang, Y., Yao, L., Wang, L., Ji, D., Tang, G., Zhang, J., Sun, Y., Hu, B., Xin, J., Mechanism for the formation of the January 2013 heavy haze pollution episode over central and eastern China, Sci. China Earth Sci., 57: 14. doi:10.1007/s11430-013-4773-4, 2014.

Wiedinmyer, C., Akagi, S. K., Yokelson, R. J., Emmons, L. K., Al-Saadi, J. A., Orlando, J. J., and Soja, A. J.: The Fire INventory from NCAR (FINN): a high resolution global model to estimate the emissions from open burning, Geosci. Model Dev., 4, 625-641, doi:10.5194/gmd-4-625-2011, 2011.

Willmott, C.J., Robeson, S.M., Matsuura, K., A refined index of model performance. International Journal of Climatology 32, 2088-2094. http://dx.doi.org/10.1002/joc.2419, 2012.

Wilks, D.S., Statistical Methods in the Atmospheric Sciences, 2nd Edition, Elsevier, New York, 2006.

Wu, Q., Wang, Z., Chen, H., Zhou, W., Wenig, M., An evaluation of air quality modeling over the Pearl River Delta during November 2006, Meteorol. Atmos. Phys., 116: 113. doi:10.1007/s00703-011-0179$\mathrm{z}, 2012$.

Zaveri, R. A., Easter, R. C., Fast, J. D., Peters, L. K., Model for Simulating Aerosol Interactions and Chemistry (MOSAIC), J. Geophys. Res., 113, D13204, doi:10.1029/2007JD008782, 2008.

Zhao, X. J., Zhao, P. S., Xu, J., Meng, W., Pu, W. W., Dong, F., He, D., and Shi, Q. F.: Analysis of a winter regional haze event and its formation mechanism in the North China Plain, Atmos. Chem. Phys., 13, 5685-5696, doi:10.5194/acp-13-5685-2013, 2013.

Zhang, L., Jacob, D. J., Kopacz, M., Henze, D. K., Singh, K., and Jaffe, D. A., Intercontinental source attribution of ozone pollution at western U.S. sites using an adjoint method, Geophys. Res. Lett., 36, L11810, doi:10.1029/2009GL037950, 2009.

Zhang, Y.,Wen, X.-Y., and Jang, C., Simulating chemistry-aerosol-cloud-radiation-climate feedbacks over the continental US using the online-coupled Weather Research Forecasting Model with chemistry (WRF/Chem), Atmos. Environ., 44, 3568-3582, 2010. 
1356 Zhang, B., Wang, Y., and Hao, J., Simulating aerosol-radiation-cloud feedbacks on meteorology and 1357 air quality over eastern China under severe haze conditions in winter, Atmos. Chem. Phys., 15, 23871358 2404, doi:10.5194/acp-15-2387-2015, 2015.

1359

1360 Xu, J., Zhang, Y., Fu, J.S., Zheng, S., Wang, W., Process analysis of typical summertime ozone 1361 episodes over the Beijing area, Science of The Total Environment, Volume 399, Issues 1-3, 25 July 1362 2008, Pages 147-157, ISSN 0048-9697, http://dx.doi.org/10.1016/j.scitotenv.2008.02.013, 2008. 